Platform companies such as Alibaba.com increasingly rely on search advertising as a revenue source. This study examines (1) the direct effect of new and existing buyers and sellers on platform advertising revenue, (2) their indirect effect through two intermediary performance variables (buyer's click rate and seller's click price), and (3) how the effects differ between launch and mature stages of the search advertising service. Unique data collected from a leading transactional business-to-business electronic platform suggest that new buyers click on more search advertisements than existing buyers, especially after the firm's buyers and sellers have learned and adapted to the service (mature stage). New sellers tend to outbid existing sellers in the mature stage, but the opposite is true when the service is newly introduced (launch stage). Because existing sellers can more effectively send quality signals in the launch stage, attracting existing, rather than new, sellers has a greater effect on click rate in the launch stage; however, the opposite is true in the mature stage. Attracting new buyers also has a greater effect on click rate and price, especially in the mature stage. Finally, using cost data from the platform, this article examines the economic returns of attracting new and existing buyers and sellers with respect to advertising revenue.

Keywords: search advertising, platform, price per click, click-through rate, network effects

\title{
Direct and Indirect Effects of Buyers and Sellers on Search Advertising Revenues in Business-to-Business Electronic Platforms
}

*Eric (Er) Fang is Associate Professor of Marketing and James Tower Faculty Fellow, University of Illinois at Urbana-Champaign, and Distinguished Visiting Professor of Marketing, Nanjing University (e-mail: erfang@illinois.edu). Xiaoling Li is corresponding author and Assistant Professor of Marketing, School of MBA and Business Administration, Zhongnan University of Economics and Law (e-mail: lixiaoling@znufe. edu.cn). Minxue Huang is Professor of Marketing, Economics and Management School, Wuhan University (e-mail: huangminxue@whu.edu.cn). Robert W. Palmatier is Professor of Marketing and John C. Narver Chair of Business Administration, Foster School of Business, University of Washington (e-mail: palmatrw@uw.edu). The second author acknowledges the financial support of the National Science Foundation of China Grant (No. 71202180), and the third author acknowledges the financial support of The National Natural Science Foundation of China (No. 71372127). Eric Bradlow served as associate editor for this article.
Recent technological innovations have led to the emergence of online platforms that create two-sided markets (e.g., eBay, Alibaba; see Grewal, Chakravarty, and Saini 2010). Revenues for platform firms come from commissions and advertising. However, to quickly build market share, many firms adopt a "freemium" strategy in which they do not charge commissions but rather rely on search advertising (Pauwels and Weiss 2008). In the United States, search advertising revenues are increasing quickly $(20 \%$ annually) and are expected to reach $\$ 22$ billion by 2015 , which is largely attributable to growth at platform firms (eMarketer 2011). Because platform firms "must get both buyers and sellers on board" to grow advertising revenue, a 
key focus of their marketing strategy is to attract both new and existing buyers and sellers to their platform simultaneously (Zhu and Iansiti 2012, p. 88). Increasing the complexity of these efforts, firms have recognized that the effectiveness of incentives changes as platform participants learn and adapt to new search advertising services (Zhang et al. 2012). Thus, the focus of the article is to understand the simultaneous effects of incentivizing new and existing buyers and sellers on search advertising revenue during the initial services launch stage (i.e., as buyers and sellers learn about the new service on the firm's platform) and after their service offering matures.

Extant research has addressed this complex problem in a piecemeal fashion. Tucker and Zhang (2010) find that sellers prefer platforms with many other sellers because this helps attract more buyers. At the individual advertiser and customer levels, Yao and Mela (2011) find evidence of dynamic bidding behaviors such that advertisers' value for clicks averages $\$ .26$, and a small portion of consumers $(10 \%)$ contribute most of the clicks $(90 \%)$. At the customer level, Rutz and Bucklin (2011) propose a dynamic linear model to capture potential spillover from generic to branded paid search, and Yang and Ghose (2010) find positive interdependence between organic search and sponsored search advertising. At the keyword level, Rutz, Trusov, and Bucklin (2011) examine the indirect effect of keywords on future site visits through "direct type-in." However, with the exception of Yao and Mela (2011), existing research has modeled either seller-side bidding behaviors or buyer-side clicking behaviors, but not both.

We extend and integrate this previous research in multiple ways, as summarized in Table 1. First, we model how marketing efforts to attract new and existing buyers and sellers can contribute to platform search advertising revenues. Second, we simultaneously examine both sellers' click price and buyers' click rate behaviors as dual mediating mechanisms linking marketing efforts to advertising revenues. Third, we compare this complex pattern of relationships across a platform firm's launch and mature stages to understand the most effective marketing strategies when a search advertising service is initially launched and after the firm's buyers and sellers have learned and adapted to the service. ${ }^{1}$

Specifically, using buyer and seller time-series data of more than 800 days aggregated at the platform level, we model the direct and mediated (through click price and click rate) effects of marketing efforts on the platform's advertising revenue. A unique temporal aspect of these data is that they cover the firm's launch of a new search advertising service into its ongoing two-sided buyer-seller marketplace, which enables us, first, to empirically identify the stages and, second, to estimate and compare different models for each stage. Vector autoregressive (VAR) analyses help reveal the dynamic, complex interdependencies among the variables.

\footnotetext{
${ }^{1}$ It is important to recognize that "stage" refers to the developmental process after launching a new advertising service offering to the participants of a specific platform firm's two-sided marketplace. These stages are different than the overall market or industry life-cycle stage.
}

The article offers several key insights. First, our aggregate platform analysis (VAR model) suggests that existing sellers have a greater effect on click rate than new sellers in the launch stage, but the opposite is true in the mature stage. Alternatively, attracting new buyers exerts a greater effect on click rate and price than does attracting existing buyers in both stages, but this effect is more pronounced in the mature stage. This provides managers insight into the most effective approach for increasing search advertising revenue for both new and existing buyers and sellers across "stages." Individual response modeling sheds light on the dynamic reach of these effects on advertising revenues, whereby the effect of attracting new buyers on revenue not only was the largest but also lasted three times longer than that for existing buyers.

Second, attracting buyers increases click price on the seller side, and attracting sellers increases click rate on the buyer side, which demonstrates a strong cross-network effect in two-sided markets. These findings provide empirical support for prior analytical studies that have modeled these effects (e.g., Katona and Sarvary 2010; Xu, Chen, and Whinston 2011). Further research on two-sided markets must simultaneously account for both direct and cross-network effects of platform participants to capture the net effect on platform behaviors and performance.

Third, our supplementary individual- and keyword-level analyses provide support for the underlying behavioral assumption we use to develop our aggregate platform-level conceptual model and hypotheses. Specifically, individual and keyword analyses on buyer clicking and seller bidding behaviors show that they differ between new and existing buyers and sellers as well as across the two stages of search advertising. New buyers tend to click on more search advertisements than existing buyers, especially in the mature stage; new sellers tend to outbid existing sellers in the mature stage, but the reverse is true in the launch stage. The results of the keyword-level analysis show that existing sellers are better able to leverage keyword bidding prices and popularity to send quality signals to and generate awareness among buyers in the launch stage, whereas new sellers are better able to do so in the mature stage.

Fourth, by incorporating the marketing costs, we calculate the economic returns from efforts to attract buyers and sellers on advertising revenue. For example, in the launch stage, a $\$ 1$ investment in attracting new buyers generated more than $\$ 5$ in search advertising revenues, whereas in the mature stage this return increased to more than $\$ 10$. However, providing bidding credits of $\$ 1$ to incentivize sellers yielded from $\$ .07$ to $\$ .26$ (depending on new/existing sellers and stages). Although these values seem low, they are not "real" money spent by the platform but rather the "free" bidding the platform offers sellers. Understanding the economic impact of attracting buyers and sellers across stages has significant managerial implications in terms of how to allocate resources to various customer relationship management efforts and optimize returns on a platform's search advertising investments (Rust, Lemon, and Zeithaml 2004).

\section{PLATFORM-BASED SEARCH ADVERTISING}

In a platform-based search advertising setting, a platform firm hosts a bidding system in which sellers typically bid on 


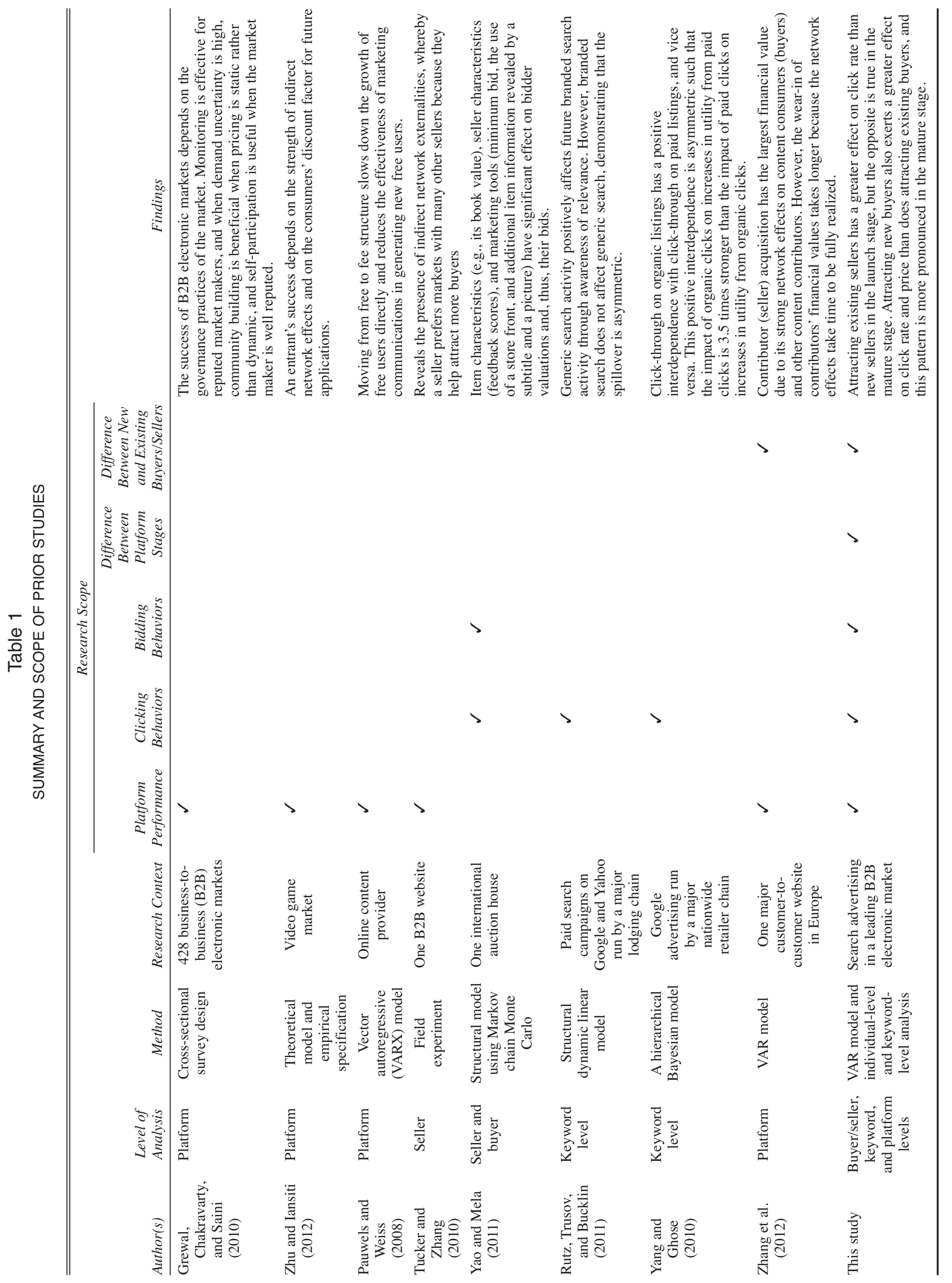


keyword phrases that are relevant to their targeted buyers, and sellers pay the platform when the search results in a click. In such a system, sellers compete and reveal the amount they are willing to pay for a click. Advertising order depends on factors such as the bidding price, the match between a specific query and the seller's product, and other seller characteristics. For each keyword query, the platform highlights a certain number of sponsored search results, which appear together with the organic search results. In most cases, the platform adopts a second-price, auctionstyle bidding process in which the advertisement by the seller with the highest bid typically shows first. However, the highest bidder pays the price bid by the second-highest bidder, and so on for other bidders. Buyers use search advertising to identify and compare options before making a purchasing decision at no cost. Automated bidding occurs daily. Although search-advertising revenues flow directly from sellers, payments are only triggered when potential buyers click on their advertisement. Thus, search-advertising revenue depends on the dynamic alignment of the seller's bidding behavior and the buyer's clicking behavior.

Aggregating these individual seller and buyer behaviors across the overall two-sided platform results in two key mechanisms that link a firm's marketing efforts to buyers and its advertising revenues to sellers. First, price per click ("click price") is the average price sellers pay for a click on an ad across all search result pages in a given day. For a platform firm, click price is an aggregate dynamic indicator of sellers' perceived value in gaining access to potential buyers. Click price is responsive to the platform firm's marketing efforts to attract buyers to its platform as sellers bid to improve their ranking on search results. Click price is also responsive to the firm's efforts to attract more sellers because a larger number of sellers will competitively bid up the price for keywords (Yao and Mela 2011).

Second, the buyer's click-through rate ("click rate") is the average number of ads that a buyer clicks on for each search result in a given day. For a platform firm, click rate is an aggregate dynamic indicator of buyers' perceived fit of the search results to their purchase needs. Click rate is responsive to the firm's efforts to attract more sellers to its platform because more sellers will improve product assortment. Click rate is also responsive to firm efforts to attract buyers to specific "product categories" because these better-fitting buyers will be more likely to click on more ads in a given search (Yang and Ghose 2010). Table 2 summarizes our key terms and definitions.

Recognizing the importance of attracting buyers and sellers to increase click price, click rate, and, ultimately, overall aggregate advertising revenue, platform firms incentivize buyers and sellers. For example, sellers that are new to the firm ("new sellers") and sellers that have previously offered products on the platform ("existing sellers") are offered bid incentives such as discounts on keywords to promote seller acquisition and expansion. Similarly, buyers that are new to the firm ("new buyers") and buyers that have previously clicked on search ads ("existing buyers") are attracted to the two-sided market using "external advertising" links and social media to promote buyer acquisition and expansion. For example, firms use advertising links on relevant keywords from search engines (e.g., Google) to attract buyers to the platform.

After launching search advertising as a new service offering to customers, a platform firm's two-sided markets often

Table 2

VARIABLES, DEFINITIONS, AND MEASURES

\begin{tabular}{|c|c|c|}
\hline Label & Definitions & Measurement \\
\hline $\begin{array}{l}\text { Search advertising } \\
\text { service launch stage } \\
\text { (launch) }\end{array}$ & $\begin{array}{l}\text { The initial developmental period when search advertising is } \\
\text { newly added to an e-commerce platform }\end{array}$ & $\begin{array}{l}\text { Period from April 1, } 2009 \text { (inception date of advertising search } \\
\text { service), to December 15, 2009, or a 258-day launch stage with } \\
\text { no structural breaks in the data }\end{array}$ \\
\hline $\begin{array}{l}\text { Search advertising } \\
\text { service mature stage } \\
\quad \text { (mature) }\end{array}$ & $\begin{array}{l}\text { The period when buyers and sellers have learned and adapted } \\
\text { to the new service and participant behaviors has stabilized }\end{array}$ & $\begin{array}{l}\text { Period from November } 20,2010 \text {, to August } 31,2011 \text {, which } \\
\text { constitutes the } 284 \text {-day mature stage with no structural breaks } \\
\text { in the data }\end{array}$ \\
\hline $\begin{array}{l}\text { Incentivized new buyers } \\
\text { (new buyers) }\end{array}$ & $\begin{array}{l}\text { New-to-the-firm buyers that conduct a keyword search in } \\
\text { response to an external advertising link (e.g., Google, Bing) }\end{array}$ & $\begin{array}{l}\text { Daily number of new buyers that conduct keyword searches } \\
\text { through external advertising links }\end{array}$ \\
\hline $\begin{array}{l}\text { Incentivized existing } \\
\text { buyers }\end{array}$ & $\begin{array}{l}\text { Returning buyers that conduct a keyword search in response to } \\
\text { an internally generated link (through, e.g., internal advertising, } \\
\text { instant messaging) }\end{array}$ & $\begin{array}{l}\text { Daily number of existing buyers that use keyword searches } \\
\text { through links to referent information on the platform }\end{array}$ \\
\hline Incentivized new sellers & $\begin{array}{l}\text { New-to-the-firm sellers that offer a keyword bid in response to } \\
\text { a marketing incentive (e.g., bid discount) }\end{array}$ & $\begin{array}{l}\text { Daily number of new sellers that participate in bidding because } \\
\text { of subsidies provided by the platform }\end{array}$ \\
\hline $\begin{array}{l}\text { Incentivized existing } \\
\text { sellers }\end{array}$ & $\begin{array}{l}\text { Returning sellers that offer a keyword bid in response to a } \\
\text { marketing incentive (e.g., bid discount) }\end{array}$ & $\begin{array}{l}\text { Daily number of existing sellers that participate in bidding } \\
\text { because of subsidies provided by the platform }\end{array}$ \\
\hline $\begin{array}{l}\text { Buyer's click-through } \\
\text { rate (click rate) }\end{array}$ & $\begin{array}{l}\text { For a platform firm, "click rate" is an aggregate dynamic } \\
\text { (daily) indicator of buyers" perceived fit of the search results } \\
\text { to their purchase needs. }\end{array}$ & $\begin{array}{l}\text { The average number of ads that a buyer clicks on for each } \\
\text { search result in a given day }\end{array}$ \\
\hline $\begin{array}{l}\text { Seller's price per click } \\
\text { (click price) }\end{array}$ & $\begin{array}{l}\text { For a platform firm, "click price" is an aggregate dynamic } \\
\text { (daily) indicator of sellers' perceived value in gaining access } \\
\text { to potential buyers of their product. }\end{array}$ & $\begin{array}{l}\text { The average price paid by sellers for a click on an ad across all } \\
\text { search result pages in a given day }\end{array}$ \\
\hline $\begin{array}{l}\text { Platform firm } \\
\text { advertising revenue }\end{array}$ & $\begin{array}{l}\text { Total search advertising revenue a platform firm earns from } \\
\text { sellers from keyword bids }\end{array}$ & Daily dollar advertising revenue of platform \\
\hline
\end{tabular}


pass through transitional stages. Because researchers argue that platform participants learn and adapt to a new service offering, it is important to distinguish launch and mature stages (Zhang et al. 2012). The initial developmental period after search advertising is newly added to an e-commerce platform is the search advertising service launch stage ("launch"). The period when buyers and sellers have learned and adapted to the new service and behaviors have stabilized is the search advertising service mature stage ("mature"). It is important to study the pattern of relationships in launch and mature stages separately to prevent aggregation bias when the marketing strategy is not optimal for either stage.

\section{CONCEPTUAL FRAMEWORK AND HYPOTHESES}

We develop an overall conceptual model and hypotheses to capture the indirect (click price and click rate) and direct effects of incentivized new and existing buyers and sellers on platform advertising revenue. In addition, we hypothesize how these complex relationships vary across launch and mature stages. Figure 1 provides an overview of our conceptual model.

\section{Effects of Incentivized Sellers on Mediating Behaviors} Across Launch and Mature Stages

Sellers can bid on popular keywords to generate buyers' awareness and attract them to their products on two-sided platforms. However, immediately after a new search adver- tising service is introduced, ranking rules are still in the process of being refined, and it is unclear which keywords are "popular." In this launch stage, because existing sellers are more knowledgeable about buyers on the platform and may already have used the search advertising feature (less perceived risk), they are more likely to leverage their experiences by bidding on popular keywords to make buyers aware of their products, generate more buyer clicks, and ultimately increase product sales. New sellers lack such experience and thus are less likely to use search advertising (higher perceived risk) in the launch stage. The opposite is true in the mature stage because the ranking rules are known and the popular keyword list is well established and available to both new and existing sellers (equal information and similar risk). However, in the mature stage, new sellers have no buyers or history on the platform to signal their product quality (e.g., no reviews), which makes new sellers more motivated to outbid existing sellers on popular keywords to generate awareness among potential buyers. Thus, existing sellers are more likely to use search advertising to generate buyer awareness in the launch stage, while new sellers tend to do so in the mature stage.

Next, we turn to the buyer's perspective in the two-sided platform. Buyers face an adverse selection problem because they cannot easily differentiate high- and low-quality sellers; in addition, sellers that lack the resources to provide high-quality products may make misleading claims (Eisen-

Figure 1

DIRECT AND INDIRECT EFFECTS OF INCENTIVIZING BUYERS AND SELLERS ON PLATFORM ADVERTISING REVENUE

Two-Sided Market

Participants

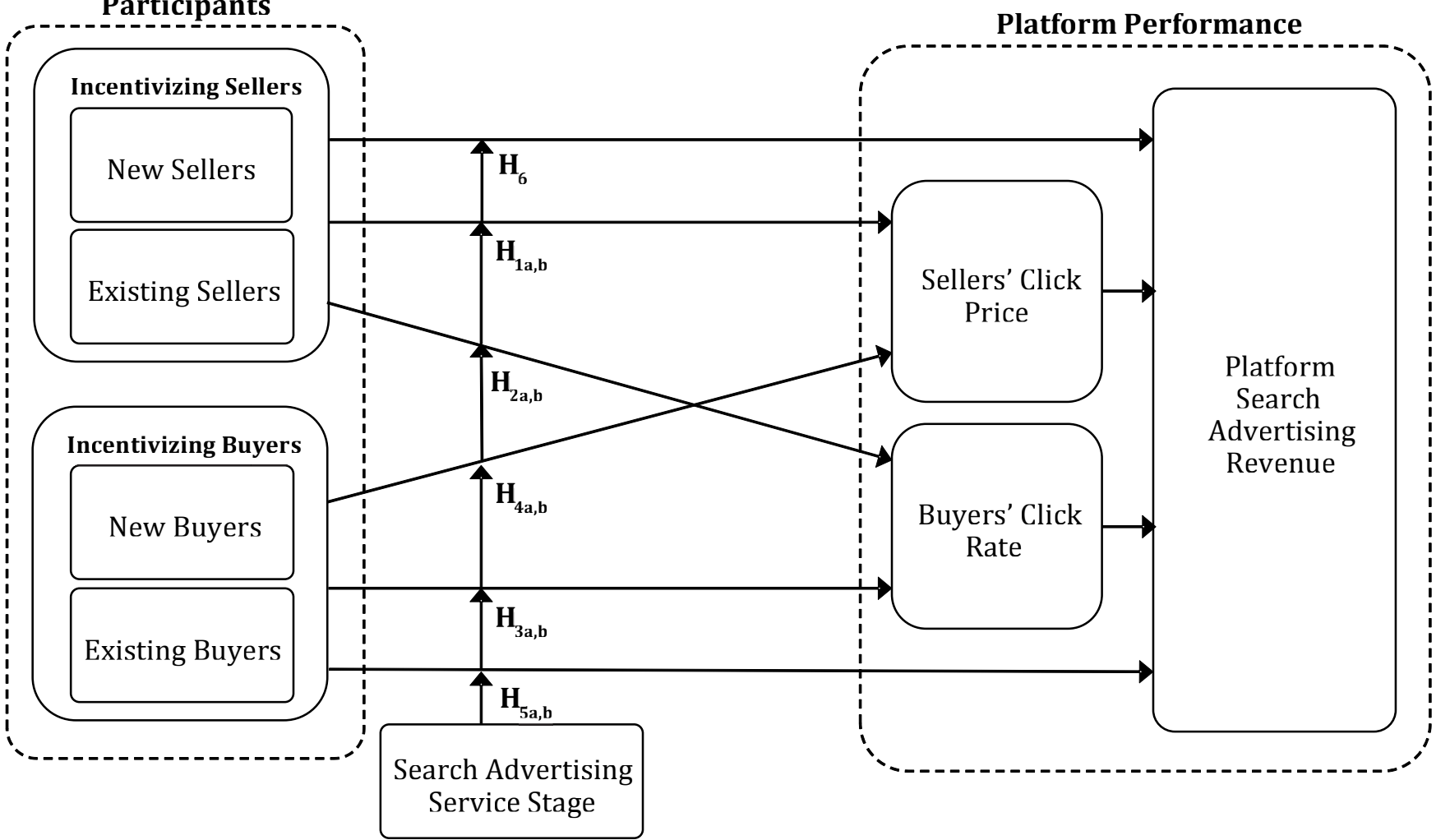


hardt 1989; Mishra, Heide, and Cort 1998). Sellers' participation in search advertising provides quality signals that help buyers solve this problem (Feng and Xie 2012). Sellers' quality signals arise because the funds they spend on search advertising depend on the number of clicks they receive, independent of a click converting to an actual sale, so only sellers with higher-quality products are likely to generate sufficient return from search advertising. The strength of quality signals is reinforced by a platform's safeguard procedures, which prevent sellers from making fraudulent product claims and increase buyers' trust in the search results.

However, the effect of these quality signals varies across new and existing buyers as the search advertising service matures. Specifically, in the mature stage, the platform firm is better able to provide institutional safeguards (e.g., punishment for falsifying product quality claims), and buyers' trust in the search results strengthens (Grewal, Chakravarty, and Saini 2010), which is more critical for new than for existing sellers. Because new sellers lack alternative sources (e.g., buyer reviews) to indicate quality, they are more likely to rely on the more robust search advertising's quality signal in the mature stage. However, in the launch stage, the weaker search advertising quality signal is not a barrier to existing sellers that use search advertising because they have alternative quality indicators (e.g., transaction histories, buyer reviews) to complement their search advertising to help overcome buyers' lack of trust. Thus, in the launch stage, existing sellers are more likely to use search advertising to send quality signals to buyers, whereas new sellers tend to do so in the mature stage. Aggregating these different effects between new and existing sellers to the platform level suggests that incentivizing more new sellers to participate in the service leads to a higher average click price in the mature stage, whereas the opposite is true in the launch stage.

$\mathrm{H}_{1 \mathrm{a}}$ : In the launch stage, the positive effect of seller bid incentives on sellers' click price is greater for existing than for new sellers.

$\mathrm{H}_{1 \mathrm{~b}}$ : In the mature stage, the positive effect of seller bid incentives on sellers' click price is greater for new than for existing sellers.

Providing bid incentives to sellers to participate in search advertising affects not only sellers' click pricing behaviors but also the other mediating behavioral mechanism linking incentives to advertising revenues/buyers' click rate. Specifically, incentivizing existing sellers to participate in bidding activities should have a greater impact on click rate than incentivizing new sellers in the launch stage, whereas the opposite should be true in the mature stage. We combine the previous argument for the effects of seller incentives on click price with prior research showing that when a seller pays more per click, it is more motivated to improve its keywordproduct alignment (i.e., quality effect), thus leading to higher buyer click rates (Athey and Ellison 2011; Xu, Chen, and Whinston 2011). In the launch stage, higher bid prices paid by more informed existing sellers motivate sellers to improve their keyword match quality, so bid incentives exert a greater effect on click rate for existing than for new sellers. In the mature stage, because new sellers tend to out- bid existing sellers due to their greater need for awareness, they are more motivated to improve their keyword-match quality, so bid incentives exert a greater effect on click rate for new than for existing sellers.

$\mathrm{H}_{2 \mathrm{a}}$ : In the launch stage, the positive effect of seller bid incentives on buyers' click rate is greater for existing than for new sellers.

$\mathrm{H}_{2 \mathrm{~b}}$ : In the mature stage, the positive effect of seller bid incentives on buyers' click rate is greater for new than for existing sellers.

\section{Effects of Incentivized Buyers on Mediating Behaviors Across Launch and Mature Stages}

The inability to differentiate high and low product quality poses a serious risk for buyers. As we have discussed, search advertising provides quality signaling benefits and helps buyers reduce the risk of selecting low-quality products (Kirmani and Rao 2000). In addition, search advertising helps buyers find products that match their idiosyncratic needs (Carson et al. 1999). Overall, search advertising is an effective tool to help buyers search for relevant product/seller information because it relates directly to buyer-generated queries and is less intrusive than other forms of online advertising (Yang and Ghose 2010). However, these search advertising benefits should be more important to new than to existing buyers because new buyers lack transaction history both on the platform and with known sellers, so they rely more on search advertising to find high-quality, wellmatched sellers. In contrast, existing buyers have a transaction history on the platform and may have already used the feature to search, so they use search advertising less frequently (i.e., fewer clicks on different ads) to find sellers (Dou et al. 2010). Thus, attracting new buyers to participate in search advertising should have a greater effect on their use of search information (i.e., click rate) than attracting existing buyers.

We expect that the differential benefits for new versus existing buyers will be greater in the mature stage than in the launch stage. In the mature stage, as the number and diversity of sellers and auctioned keywords increases, new buyers rely even more on search advertising to identify well-matched products among the larger and more diversified consideration set. Existing buyers, in contrast, have already developed their search heuristics and reduced their consideration set, so they will use search advertising less than new buyers (Gu et al. 2010). Therefore, new buyers tend to click on more ads than existing buyers, and this effect is larger in the mature stage. Aggregating these differences between new and existing buyers to the platform level suggests that attracting more new buyers to participate in the service leads to a higher average click rate than attracting existing buyers, and the difference is larger in the mature stage.

$\mathrm{H}_{3 \mathrm{a}}$ : In both stages, the positive effect of advertising to attract buyers on click rates is greater for new than for existing buyers.

$\mathrm{H}_{3 \mathrm{~b}}$ : The differential effect of advertising to attract buyers on click rates for new versus existing buyers is larger in the mature stage.

Attracting buyers using external advertising links affects not only buyers' click-rate behaviors but also the other 
mediating behavioral mechanism linking marketing efforts to advertising revenues/sellers' click price. Specifically, the effect of attracting buyers to the online platform on sellers' click price is greater for new than for existing buyers. Sellers will perceive a higher value in a keyword, reflected in their bid price, if there are more new buyers clicking on their ads (Katona and Sarvary 2010). At the platform level, sellers perceive more value because a market platform has more new buyers in both stages (Athey and Ellison 2011).

This difference is larger in the mature stage than in the launch stage because, in the beginning, new buyers conduct an extensive search-and-learn process in which most searches do not result in purchases, thus undermining the value of any one click (i.e., low conversion for a new buyer click). However, as the online platform matures and information becomes more available (e.g., reviews), new buyer search behavior becomes more efficient. This results in higher conversion to sales for new buyer clicks, so sellers bid up the price for the more valuable new buyers' clicks in the mature stage.

\section{$\mathrm{H}_{4 \mathrm{a}}$ : In both stages, the positive effect of advertising to attract buyers on sellers' click price is greater for new than for existing buyers. \\ $\mathrm{H}_{4 \mathrm{~b}}$ : The differential effect of advertising to attract buyers on sellers' click price for new versus existing buyers is larger in the mature stage.}

\section{Direct Effects of Incentivized Buyers and Sellers on Advertising Revenues Across Stages}

Marketing efforts to attract new buyers and sellers have a direct effect on advertising revenues in addition to their indirect effect through click price and rate. The value of a two-sided market's offerings to buyers depends on the number of sellers in the market, and vice versa, which leads to a "network effect" whereby the value of the offering to users increases as the number of buyers and sellers increases (Katz and Shapiro 1994, p. 97; Wang and Xie 2011). Twosided market network effects arise in two ways. First, the growing number of buyers and sellers on the platform signals their confidence in the platform and thus increases other potential buyers' and sellers' evaluations of the platform. Second, as the number of buyers and sellers increases, price and product competition among sellers intensifies, which increases the value of the offering to buyers. Due to these network effects in two-sided market platforms, attracting new buyers and sellers has a greater direct effect on platform advertising revenues than attracting existing buyers and sellers because only acquiring new participants helps firm build its installed base with a multiplier effect on future revenues. Attracting existing sellers and buyers does not change the installed base, so the network effect benefits do not occur. These effects occur in both stages.

Moreover, the conversion rate for clicks to purchases for buyers is higher in the mature stage, given that buyers have a higher level of trust in search results as the service matures (Grewal, Chakravarty, and Saini 2010). Thus, the differential effect of attracting a buyer on advertising revenue for new versus existing buyers is larger in the mature stage than in the launch stage.
$\mathrm{H}_{5 a}$ : In both stages, the direct positive effect of advertising to attract buyers on platform advertising revenue is greater for new than for existing buyers.

$\mathrm{H}_{5 \mathrm{~b}}$ : The differential effect of advertising to attract buyers on platform advertising revenue for new versus existing buyers is larger in the mature stage.

$\mathrm{H}_{6}$ : In both stages, the direct positive effect of seller bid incentives on platform advertising revenue is greater for new than for existing sellers.

\section{METHODOLOGY}

\section{Research Context}

We conducted this study with the cooperation of a leading business-to-business (B2B) online platform company. The company was founded in 1999 and has become a global ecommerce leader, supporting small businesses in 45 industries including automobile parts, apparel, and food. Its 76 million users from more than 70 countries include 66 million buyers and 10 million sellers, which conduct $\$ 4.5$ billion worth of online transactions daily. Most buyers and sellers are small businesses, attracted by the platform's "freemium" strategy. Since 2009, the firm has provided keyword search advertising services to sellers. This offer is part of the firm's effort to help sellers manage their online businesses and to create new revenue sources. The platform offers certain keywords in auctions, and sellers bid for their appearance and order in the results list. In particular, each seller signs a contract with the platform and places a certain amount of money into its bidding account, which it can use to pay for its bids. The platform runs an automatic bidding process each day for each keyword, at which time each participating seller informs the platform of the maximum amount it is willing to pay for each resulting click. The platform displays the seller's advertising in accordance with the bidding price. Search results appear adjacent to organic results, with a "promotion" logo on top. Similar to other search advertising services, the platform adopts secondprice, auction-style bidding.

To encourage sellers to participate, the platform offers promotions, such as bidding credits that new and existing sellers can use to pay for advertising clicks. To increase click rates, the platform also advertises to buyers through two channels. First, it relies on external search engines (e.g., Google) to advertise its services and attract new buyers that have not used the service. A new buyer might search for a certain keyword on Google and be directed to the platform's search results page. Second, the platform attracts existing buyers using personal referent advertising. These tactics often entail sending some favorite advertisements, according to the user's history, to motivate existing buyers to pay attention to a specific product. The firm tracks new and existing buyer and seller incentives, click rates, click prices, and platform advertising revenue on a daily basis, which we use in our analysis. Table 2 provides an overview of the study variables' definitions and measures.

\section{Model Analysis Approach}

Our model analysis involves two key steps. First, we empirically divide our observations into launch and mature stages. Second, we estimate our model for each stage sepa- 
rately and compare the relevant coefficients at the aggregateplatform level to test the hypotheses.

Step 1: Identification of launch and mature stages. We collected 882 days of data from April 1, 2009 (inception date of the advertising service), to August 31, 2011. We used a rolling-window approach to identify the two stages. We needed sufficiently long windows to ensure robust model estimation, and within each period the parameters must remain stable. Consistent with prior studies (Joshi and Hanssens 2010), we conducted rolling-window, augmented Dickey-Fuller (ADF) unit root tests with 100-day observation windows (Zhang et al. 2012), moving the window along the time series of 882 days. For the launch stage, we moved the rolling window from April 1, 2009, to the date at which we found a structural break - that is, when the ADF test failed to reject the presence of unit roots for any of the variables at the 5\% level. We used the same approach to identify the mature stage, moving the rolling window backward from August 31, 2011. The results suggested one period from April 1 to December 15, 2009, or a 258-day launch stage, and another period from November 20, 2010, to August 31, 2011, which constituted the 284-day mature stage. Within each period, we performed the ADF unit root test to address the null hypothesis (Enders 1995). The results rejected the presence of unit roots for all variables at the $5 \%$ level (see Table 3 ). Thus, we divide our data into two periods, termed launch and mature stages, in which each stage is temporally homogeneous and does not include any structural breaks. Bidding by sellers and clicking by buyers increased more than $150 \%$ from the launch to the mature stage.

Interviews with managers from the platform company confirmed these time frames as representative of the launch and mature stages. In the first few months after the inception of the search, the platform company did not make significant changes to the ranking rules or other service items, because it wanted to provide consistent experiences to buyers and sellers. As of early 2010, in collaboration with thirdparty service firms, it began providing value-added services such as search optimization to enhance sellers' bidding and buyers' search effectiveness. While keeping its basic model of buyer and seller interactions intact, the platform optimized its search results display in response to feedback from clients. Such changes took place over several months, reaching stability in late 2010 . In addition, since late 2010 , the platform began to regularly provide popular keyword

Table 3

UNIT ROOT TEST RESULTS

\begin{tabular}{|c|c|c|}
\hline$t$-Value $(A D F)$ & Introductory Stage & Established Stage \\
\hline Click price & $-4.898 *$ & $-5.564 *$ \\
\hline Click rate & $-7.203 * *$ & $-8.646 * *$ \\
\hline New buyers & $-5.293^{*}$ & $-5.547^{*}$ \\
\hline Existing buyers & $-12.948 * *$ & $-10.290 * *$ \\
\hline New sellers & $-4.900 *$ & $-6.149 *$ \\
\hline Existing sellers & $-7.938 * *$ & $-8.636 * *$ \\
\hline Advertising revenue & $-8.393 * *$ & $-8.737 * *$ \\
\hline
\end{tabular}

lists for different product categories to sellers. Thereafter, the platform did not initiate any major changes.

Step 2: Aggregate platform model estimation. For the model analysis of the aggregated data, we use a persistence modeling technique, VAR (Trusov, Bucklin, and Pauwels 2009), which captures the interdependent evolution of the variables. By treating each variable as potentially endogenous, the VAR model can reveal dynamic, complex interdependence among the variables. It also supports a flexible treatment of the cumulative effect of marketing actions on performance (Dekimpe and Hanssens 1999). We followed a standard VAR procedure (Dekimpe and Hanssens 1999), using separate analyses for the launch and mature periods:

1. We determined the appropriateness of VAR according to a Granger (1969) causality test.

2. We determined the model specification (VAR in levels, VAR in differences, or error-correction forms) according to the unit root and co-integration test results.

3. Using information criteria, we determined the model specification (number of lags).

4. We derived the impulse response functions (IRFs) for the cumulative effect.

5. By calculating the variance decomposition of new and existing buyers and sellers, we separated the direct effects on firm advertising revenues from their indirect effects through click price and click rate.

We also conducted a series of Granger causality tests to explore whether variable $\mathrm{X}$ explained variable $\mathrm{Y}$, beyond Y's own prior values, which offers a good proxy for causality. By using lags of up to 20 periods, we investigated whether we needed to model a full dynamic system. We found Granger causality, indicating the need to adopt a full dynamic VAR model.

\section{Model Specification and Estimation}

We estimated the models in levels on the basis of ADF unit root test results. We used the Schwarz Bayesian information criterion (SBIC) to determine the appropriate lags. In the launch stage, we used two-period lags (Akaike information criterion $=-31.345, \mathrm{SBIC}=-33.256)$, and in the mature stage, we used one-period lags $(\mathrm{AIC}=-31.881$, SBIC $=-32.090)$. Thus, we use a seven-variable VAR system to capture dynamic interactions among the advertising revenue (Rev), new and existing buyers, new and existing sellers, click-through rate (CTR), and price per click (PPC). We took a log-transformation to normalize advertising revenue as well as new and existing buyers and sellers. The vectors of the exogenous variables included, for each endogenous variable, an intercept $\mathrm{C}$; a deterministic-trend variable $\mathrm{T}$, which captured the impact of the omitted, gradually changing trend of the variables; and indicators for days of the week D, with Friday as the benchmark (Pauwels and Dans 2001).2

\footnotetext{
${ }^{2}$ We did not include holiday dummies for this global platform, because countries adopt different holidays.
} 


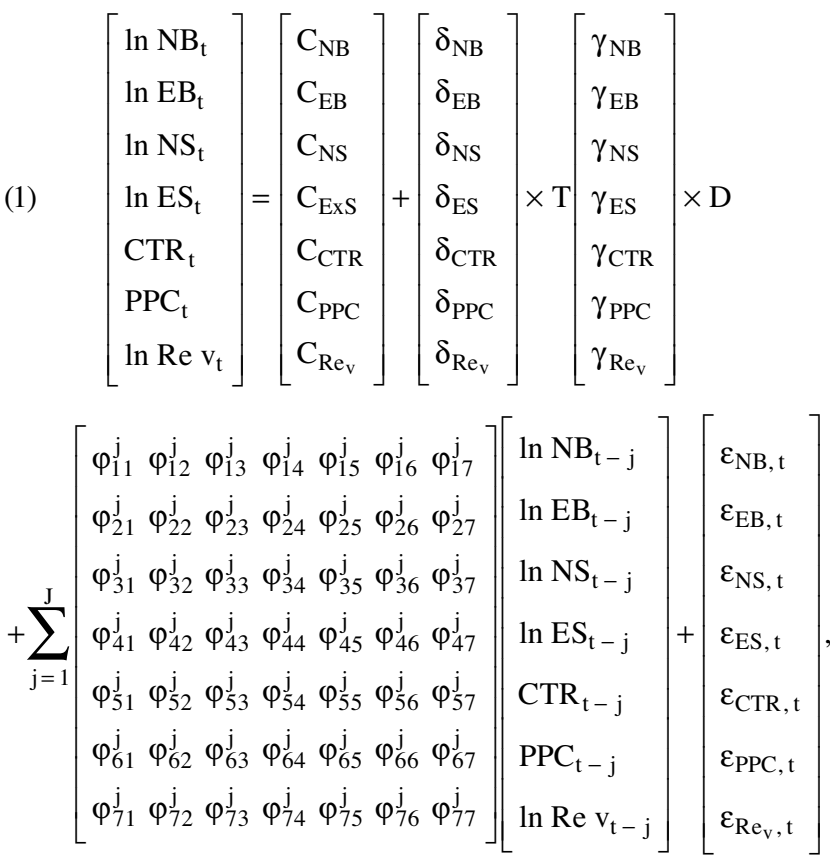

where $t$ refers to days, $\mathrm{J}$ equals the number of lags included (two for the launch stage, one for the mature stage), D is the vector of day-of-week dummies, and $\varepsilon$ are white-noise disturbances distributed as $\mathrm{N}(0, \Sigma)$. The parameters $\delta, \gamma$, and $\phi$ remain to be estimated. Because the VAR model parameters are not interpretable on their own (Sims 1980), we determined the effect sizes and significance through an analysis of the impulse response functions (IRFs) and elasticity. The R-square fit statistics were .938 in the launch and .920 in the mature stage. We also tested for the presence of serial correlation and heteroskedasticity. The large $p$-values (Lagrangemultiplier test: launch .753 , mature .848 ; White test: launch .628 , mature .724) suggest that the model error terms were white noise (Joshi and Hanssens 2010).

$I R F$. We derived IRFs to capture over-time impact of a unit shock to any endogenous variable on other endogenous variables. We used generalized IRFs to ensure that the order of variables in the system did not affect the results and to account for same-period effects (Dekimpe and Hanssens 1999). We determined the duration of the shock (maximum lag $\mathrm{k}$ ) as equal to the last period in which the IRF value had a $|\mathrm{t}|$-statistic greater than 1 . We accumulated IRFs until lag $\mathrm{k}$ as the cumulative effect of the impulse variable on the response variable (Trusov, Bucklin, and Pauwels 2009).

Variance decomposition. We calculated the forecast error variance decomposition of new and existing buyers and sellers, which equals the percentage of the forecast error variance of firm advertising revenues attributed to these buyers and sellers, separate from the contributions of click price and rate (Nijs, Srinivasan, and Pauwels 2007). This analysis enables us to separate the direct effect of new and existing buyers and sellers on firm advertising revenues from their indirect effects though click price and rate (Joshi and Hanssens 2010).

\section{RESULTS}

We are interested in the cumulative effect of new and existing buyers and sellers on click price, click rate, and advertising revenues. Advertising revenues, buyers, and sellers are all log-transformed so the coefficients can be interpreted as elasticity. For the effects of buyers and sellers on click price and click rate from the variance decomposition analysis, we converted the numbers into elasticity to aid in interpretation. We summarize the results in Table 4.

\section{Effects of Incentivized Sellers on Mediating Behaviors Across Launch and Mature Stages}

In the launch stage, incentivizing both new and existing sellers had a significant, positive effect on click price (new sellers' elasticity $=.068, p<.01$; existing sellers' elasticity $=$ $.061, p<.01)$. We use Monte Carlo simulations with 250 replications to conduct pairwise comparisons of the cumulative effects (Villanueva, Yoo, and Hanssens 2008). We used the same approach for all subsequent pairwise comparisons. The difference between new and existing sellers on click price in the launch stage was not significant (difference $=$ .007 , n.s.), so we must reject $\mathrm{H}_{1 \mathrm{a}}$. In the mature stage, incentivizing new sellers had a positive, significant effect on click price (new sellers' elasticity $=1.112, p<.01$ ), whereas incentivizing existing sellers was not significantly related to click price. The pairwise comparison between new and existing sellers on click price was significant in the mature stage (difference $=1.112, p<.01$ ), so the findings support $\mathrm{H}_{1 \mathrm{~b}}$ (i.e., the positive effect of seller bid incentives on click price was greater for new than existing sellers).

In the launch stage, incentivizing both new and existing sellers had significant, positive effects on click rate (new sellers' elasticity $=.102, p<.01$; existing sellers' elasticity $=$ $.269, p<.01)$. The pairwise comparison between existing and new sellers on click rate was significant in the launch stage (difference $=.167, p<.01$ ), so the findings support $\mathrm{H}_{2 \mathrm{a}}$ (i.e., the positive effect of seller bid incentives on buyers' click rate was greater for existing than new sellers). In the mature stage, incentivizing new sellers had a significant, positive effect on click rate (new sellers' elasticity $=.410$, $p<.01$ ), whereas incentivizing existing sellers was not significantly related to click rate. The pairwise comparison between new and existing sellers on click rate was significant in the mature stage (difference $=.372, p<.01$ ), so the findings support $\mathrm{H}_{2 b}$ (i.e., the effect of seller bid incentives on buyers' click rate is greater for new than existing sellers).

\section{Effects of Attracting Buyers on Mediating Behaviors Across Launch and Mature Stages}

Attracting new buyers using external advertising links had significant, positive effects on click rate in both the launch (new buyers' elasticity $=.730, p<.01$ ) and mature (new buyers' elasticity $=1.734, p<.01$ ) stages. However, attracting existing buyers was not significantly related to click rates in either launch or mature stages. As we hypothesized, the pairwise comparisons between new and existing buyers on click rate were significant for both stages, in support of $\mathrm{H}_{3 \mathrm{a}}$ (launch stage difference $=.730, p<.01$; mature stage difference $=1.734, p<.01)$. Thus, the effect of advertising to attract buyers on their click rates was greater for new than for existing buyers in both stages. In support of $\mathrm{H}_{3 \mathrm{~b}}$, the differential effect of advertising buyers' click rates for new versus existing buyers was larger in the mature stage than in the launch stage (difference $=1.004, p<.01$ ). 
Table 4

EFFECTS OF INCENTIVIZING BUYERS AND SELLERS ON ADVERTISING REVENUE

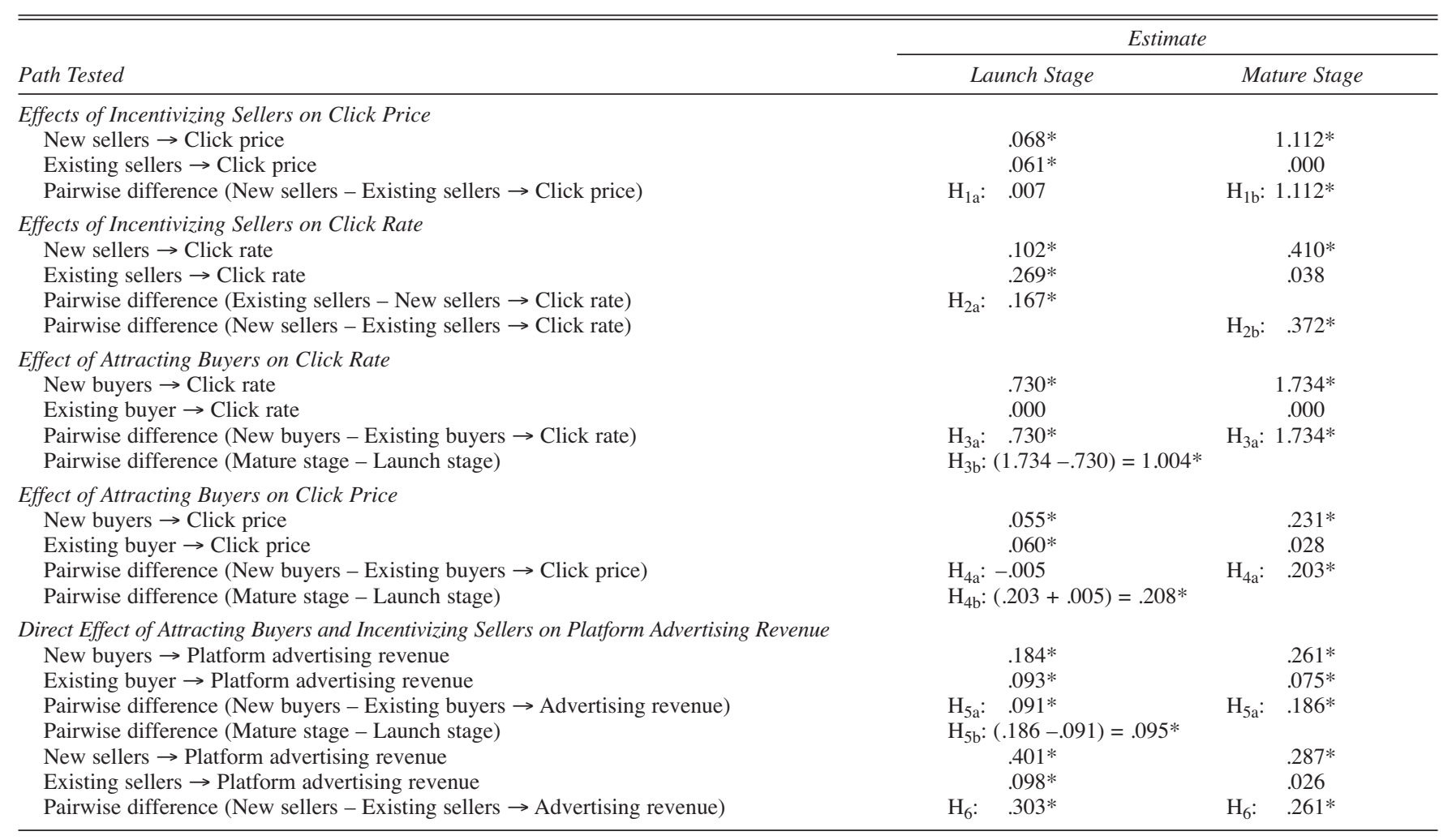

$* p<.01$.

Notes: Consistent with Villanueva, Yoo, and Hanssens (2008), we use Monte Carlo simulations with 250 replications to conduct pairwise comparisons of the cumulative effects.

Attracting new buyers using external advertising links had significant, positive effects on click price in both the launch (new buyers' elasticity $=.055, p<.01$ ) and the mature (new buyers' elasticity $=.231 p<.01$ ) stages. Although attracting existing buyers had significant, positive effects on click price in the launch stage (existing buyers' elasticity $=.060, p<.01)$, it was not significant in the mature stage. Because the pairwise comparison between new and existing buyers on click price was only significant in the mature stage (difference $=.203, p<.01$ ) but not in the launch stage, the findings only partially support $\mathrm{H}_{4 \mathrm{a}}$. Specifically, the effect of advertising to attract buyers on sellers' click price was greater for new than for existing buyers in the mature stage only. In support of $\mathrm{H}_{4 \mathrm{~b}}$, the differential effect of advertising to attract buyers on sellers' click price for new versus existing buyers was larger in the mature stage $($ difference $=.208, p<.01)$.

\section{Direct Effects of Attracting Buyers and Sellers on Advertising Revenues Across Stages}

Attracting new and existing buyers had significant, positive effects on advertising revenues in both the launch (new buyers' elasticity $=.184, p<.01$; existing buyers' elasticity $=$ $.093, p<.01$ ) and the mature (new buyers' elasticity $=.261$, $p<.01$; existing buyers' elasticity $=.075, p<.05$ ) stages. In both stages, the positive direct effect of advertising to attract buyers on advertising revenue was greater for new than for existing buyers (launch stage difference $=.091, p<.01$; mature stage difference $=.186, p<.01$ ), in support of $\mathrm{H}_{5 \mathrm{a}}$. The differential effect of advertising to attract buyers on platform advertising revenue for new versus existing buyers was larger in the mature stage than in the launch stage (difference $=.095, p<.01$ ), in support of $\mathrm{H}_{5 \mathrm{~b}}$. Incentivizing new and existing sellers had significant, positive effects on platform advertising revenues in the launch stage (new sellers' elasticity $=.401, p<.01$; existing sellers' elasticity $=$ $.098, p<.01)$, but only for new sellers in the mature stage (new sellers' elasticity $=.287, p<.01$ ). In both stages, the positive direct effect of incentivizing sellers on advertising revenue was greater for new than for existing sellers (launch stage difference $=.303, p<.01$; mature stage difference $=$ $.261, p<.01)$, in support of $\mathrm{H}_{6}$.

\section{Economic Return from Incentivizing Buyers and Sellers on Advertising Revenue}

To provide additional insight into the economic impact of marketing incentives on advertising revenue, we integrate the costs of the different marketing incentives. For both stages, we calculated economic return, defined as the revenue gains resulting from the firm's search advertising, a $\$ 1$ investment in new and existing buyers and sellers. However, we could not calculate the economic impact of attracting existing buyers, because this occurred through internal advertising and instant messaging. For the platform com- 
pany, this effort is largely free, except for some minimal administrative costs. 3 We obtained daily data from the platform on its spending on new and existing sellers in the launch and mature stages. Because no record of overall spending across external channels existed for attracting new buyers, we used the fact that spending on Google accounted for approximately $60 \%$ of the firm's overall external search spending. Thus, we multiplied this daily spending on Google by $1.67(1 / .6)$ to estimate daily spending on all external search engines.

With these daily expenditures, we calculated the cost to acquire each seller (buyer), with activity $x$ equal to the average of (daily_spending ${ }_{x} / \Delta x$ ). That is, daily spending refers to the platform's daily spending on activity $\mathrm{x}$, and $\Delta \mathrm{x}$ is the daily number of buyers (sellers) using the service as a result of this specific activity x. Next, we calculated the revenue generated by each seller (buyer) through activity $\mathrm{x}$ by converting elasticity into a dollar amount, using elasticity $\times \bar{y} / \bar{x}$, $\bar{y}$ from the mean value of advertising revenue and from the mean value of the number of buyers (sellers) using the service because of the specific activity $\mathrm{x}$. The elasticity is based on the total effect of new and existing buyers (sellers) on advertising revenues generated from the impulse function (for details, see Web Appendices A and B).

As Table 5 shows, in the launch stage, a $\$ 1$ investment in new sellers generated $\$ .07$ returns in terms of advertising revenue; in the mature stage, the return was $\$ .22$. Furthermore, a $\$ 1$ investment in existing sellers contributed $\$ .26$ in advertising revenue in the launch stage. Although these values seem low, they are not "real" money spent by the platform but rather the "free" bidding the platform offers sellers. The variable cost of sponsoring bidding activities is low (monetary cost of serving one more seller), so we consider such returns reasonable. However, the results from using external search engines to attract new buyers are managerially significant. In the launch stage, $\$ 1$ spent on new buyers generated $\$ 5.32$ in advertising revenue; in the mature stage, it delivered $\$ 10.88$. Thus, it clearly pays to use external search engines to attract new buyers to participate in the keyword search service.

${ }^{3}$ Other costs are associated with buyer responses. For example, buyers may become frustrated if they receive too many advertising messages from the platform company, which might lower conversion rates.

Table 5

ECONOMIC RETURNS FROM INCENTIVIZING BUYERS AND SELLERS

\begin{tabular}{lcc}
\hline \hline & \multicolumn{2}{c}{ Dollars Return in Advertising Revenues } \\
\cline { 2 - 3 } A \$1 Investment in: & Launch Stage & Mature Stage \\
\hline New sellers & $\$ .07$ & $\$ .22$ \\
Existing sellers & $\$ .26$ & n.s. \\
New buyers & $\$ 5.32$ & $\$ 10.88$ \\
Existing buyers & N.A. & N.A. \\
\hline
\end{tabular}

\footnotetext{
aWe could not calculate returns for existing buyers, because leads were generated from internal advertising (e.g., instant messaging), which has no costs except minor administrative overhead.

Notes: N.A. = not applicable; n.s. $=$ not significant .
}

\section{SUPPLEMENTARY ANALYSES}

We further examine our data by performing supplementary analyses to provide insight into (1) the dynamics of our results, using a response functions analysis; (2) the underlying behavioral assumptions, using individual- and keywordlevel analyses; and (3) the stability of parameter estimates, using robustness analyses. In the following subsections, we report and discuss the response functions analysis and the individual-level and keyword-level analyses to testify to our findings.

\section{Response Functions of Buyers and Sellers on Advertising Revenue}

To detail how these effects emerged over time, we analyze the response functions (for details, see Web Appendix A). New buyers had the greatest initial effect on advertising revenues and then settled into an insignificant zone after approximately two weeks. Existing buyers exerted the greatest effect on the first day and then settled into the insignificant zone more quickly by the fourth day. The impact of new sellers on advertising was significant on the first day, peaked on the second day, and then settled into a long-term effect, lasting approximately two weeks in the launch stage and four weeks in the mature stage. Finally, the effect of existing sellers was significant on the first day, peaked on the third day, and became insignificant after a week.

We note two implications of these response functions. First, the strategies for existing buyers and sellers involve a much shorter period than the strategies for new buyers and sellers, perhaps because existing buyers and sellers adjust their behaviors more quickly. Second, the effects of new and existing sellers peaked not on the first day but rather a few days later. A possible reason for this is that sellers adjust their behaviors according to performance feedback from their prior bidding behaviors. For example, more sellers participating in the service can increase competition among sellers, which leads to a high click price only after sellers realize and adjust their bidding prices. Similarly, competition improved the match of keywords with buyer demand, contributing to higher click rates. Yet these effects reached a maximum only after the sellers realized and reacted to the intensified competition.

\section{Individual-Level Analysis}

We conducted individual-level analyses to confirm specific participant behaviors that we proposed at the individual buyer and seller level but tested at the aggregate platform level to increase confidence in the underlying behavioral assumptions. Specifically, we confirm that (1) existing sellers are more likely to use search advertising to generate buyer awareness in the launch stage and new sellers tend to do so in the mature stage, and (2) new buyers tend to click more ads than existing buyers, and this effect is larger in the mature stage.

We tested these behavioral assumptions by gathering data on a random selection of approximately 10,000 individual buyers and sellers that participated in search advertising. To minimize the effect of different days of the week, we randomly picked one Monday in the launch (October 5, 2009) and mature (August 18,2011) stages. We obtained data on average click rate for each buyer, average bidding price for 
each seller, and their history (number of years since the buyer or seller began using the platform). Then, we created a stage dummy variable $(0=$ launch, $1=$ mature $)$ and interaction terms of stage with seller history and buyer history. We conducted ordinary least squares estimation to examine how seller history affected the average bidding price (click price) and how buyer history affected the average click rate in each stage. We report the results in Appendix A.

The two-way interaction effects between stage and seller history on click price $(\beta=-.034, p<.01)$ and between stage and buyer history on click rate $(\beta=-.406, p<.01)$ are significantly negative. Thus, the effects of seller history on click price and buyer history on average click rate drop as the service evolves from the launch stage to the mature stage. In addition, for sellers in the launch stage, a longer history on the platform led to a higher average bidding price $(\beta=.012, p<.05)$, whereas in the mature stage, this relationship became net negative $(\beta=-.022, p<.01 ; .012-.034=$ $-.022) .{ }^{4}$ Finally, in the launch stage, longer buyer history led to lower average click rate $(\beta=-.156, p<.01)$, and in the mature stage, the net negative effect was much stronger $(\beta=-.562, p<.01 ;-.156-.406=-.562)$. Overall, these individual-level analyses support the underpinnings of the behavioral arguments used in our hypotheses $\left(\mathrm{H}_{1 \mathrm{a}-\mathrm{b}}\right.$ and $\left.\mathrm{H}_{3 \mathrm{a}-\mathrm{b}}\right)$.

\section{Keyword-Level Analysis}

We conducted a keyword-level analysis to confirm the third behavioral assumption underlying our aggregate-level hypotheses. Specifically, in the launch stage, existing sellers are more likely to use search advertising to send quality signals and generate awareness, whereas new sellers tend to do so in the mature stage. 5 We conducted our keyword-level analysis using the same days and group of sellers as in the individual analysis. For each seller, we randomly selected one keyword that the seller used in the bidding and that reflected its product such that we had more than 3,000 keywords (with overlap among sellers). The unit of analysis is at the keyword-seller level, and the dependent variable is the number of total buyer clicks on a given keyword by a given seller in that day, which reflects the seller's effectiveness in using that keyword to attract buyers. We use keyword bidding price (average daily bidding price submitted by all participating sellers of the keyword) as a proxy for quality signals, where the higher price provides a stronger quality signal to buyers. We use keyword popularity (daily number of sellers that bid for the keyword) as a proxy for buyer awareness. We adjust measures for category heterogeneity by subtracting category-level means.

To examine how the two mechanisms differ between new and existing sellers, we created interaction effects between keyword bidding price and seller history and between keyword popularity and seller history. In addition, we included relevant three-way interactions of stage, keyword bidding price, and seller history as well as interactions of stage, keyword popularity, and seller history to test for their differ-

4The significance tests relied on a simple slope analysis (see Fang 2008; Spiller et al. 2013).

${ }^{5}$ Individual buyer data at the keyword level were not available due to privacy considerations. ences between the launch and mature stages. For detailed model specification and results, see Appendix B. The threeway interaction effects are negative and significant for both keyword bidding price $(\beta=-.254, p<.05)$ and keyword popularity $(\beta=-.178, p<.01)$. That is, the effects of the seller's history on the relationships of keyword bidding price or popularity with number of buyer clicks diminish as the service evolves from the launch to mature stage. In the launch stage, seller history has positive interaction effects on keyword bidding price $(\beta=.164, p<.01)$ and keyword popularity $(\beta=.218, p<.01)$, so sellers with long histories better leverage high-priced and more popular keywords to generate clicks from buyers. Alternatively, in the mature stage, seller history has a negative interaction effect with keyword bidding price, with marginal significance $(\beta=$ $-.090, p<.10 ;-.254+.164=-.090)$. That is, new sellers can better leverage high keyword bidding prices to generate clicks from buyers. However, in the mature stage, seller history does not have a significant interaction effect with keyword popularity $(\beta=.04$, n.s.; $-.178+.218=.040)$. Overall, these analyses provide partial support for the underpinnings of the behavioral arguments used in our hypotheses $\left(\mathrm{H}_{1 \mathrm{a}-\mathrm{b}}\right)$.

\section{Robustness Analyses}

We conducted two robustness checks. First, we tested for the stability of the parameters (i.e., whether revenue contributions of new and existing buyers and sellers change over time). In each period, we derived IRFs for new buyers, existing buyers, new sellers, and existing sellers over time, using the rolling-window data sample (100-day observation windows) and moving the window along the time series (258-day launch stage, 284-day mature stage). The parameters did not differ significantly for any two time windows, according to a pairwise significance test. Second, we used the change-point analysis Inclán and Tiao (1994) propose to divide our observations into the launch and mature stages, as we detail in Web Appendix C. The results using two periods based on a change-point analysis remain essentially the same.

\section{DISCUSSION}

Using data collected from one of the world's leading online platforms, we explore the effects of attracting new buyers, existing buyers, new sellers, and existing sellers on click rate, click price, and platform advertising revenues across two stages of search advertising (launch and mature). The platform-, individual-, and keyword-level analyses generate several theoretical and managerial implications. In Table 6, we summarize the main results of these analyses.

\section{Theoretical Implications}

This article contributes to several research streams. First, the essence of a platform company is to manage a two-sided market (Zhang et al. 2012), and its financial success depends on its ability to attract both buyers and sellers. This study sheds light on how buyers and sellers, as well as their dynamic interactions, increase platform advertising revenue. We find that strong network effects exist and manifest in two ways. First, acquiring sellers to participate in bidding increases click rate on the buyer side because of the quality effect; that is, when more sellers participate, they are moti- 
Table 6

SUMMARY OF RESULTS

\begin{tabular}{|c|c|}
\hline Hypotheses, Behavioral Assumptions, and Informational Mechanisms Tested & Outcome \\
\hline \multicolumn{2}{|l|}{ Platform-Level Analysis } \\
\hline $\mathrm{H}_{1 \mathrm{a}}$ : In the launch stage, the positive effect of seller bid incentives on sellers' click price is greater for existing than for new sellers. & Not supported \\
\hline $\mathrm{H}_{1 \mathrm{~b}}$ : In the mature stage, the positive effect of seller bid incentives on sellers' click price is greater for new than for existing sellers. & Supported \\
\hline $\mathrm{H}_{2 \mathrm{a}}$ : In the launch stage, the positive effect of seller bid incentives on buyers' click rate is greater for existing than for new sellers. & Supported \\
\hline $\mathrm{H}_{2 \mathrm{~b}}$ : In the mature stage, the positive effect of seller bid incentives on buyers' click rate is greater for new than for existing sellers. & Supported \\
\hline $\mathrm{H}_{3 \mathrm{a}}$ : In both stages, the positive effect of advertising to attract buyers on their click rates is greater for new than for existing buyers. & Supported \\
\hline $\mathrm{H}_{3 \mathrm{~b}}$ : The differential effect of advertising to attract buyers on their click rates for new versus existing buyers is larger in the mature stage. & Supported \\
\hline $\mathrm{H}_{4 \mathrm{a}}$ : In both stages, the positive effect of advertising to attract buyers on sellers' click price is greater for new than for existing buyers. & $\begin{array}{l}\text { Only supportec } \\
\text { in mature stage }\end{array}$ \\
\hline $\mathrm{H}_{4 \mathrm{~b}}$ : The differential effect of advertising to attract buyers on sellers' click price for new versus existing buyers is larger in the mature stage. & Supported \\
\hline $\begin{array}{l}\mathrm{H}_{5 \mathrm{a}} \text { : In both stages, the direct positive effect of advertising to attract buyers on platform advertising revenue is greater for new than for } \\
\text { existing buyers. }\end{array}$ & Supported \\
\hline $\begin{array}{l}\mathrm{H}_{5 \mathrm{~b}} \text { : The differential effect of advertising to attract buyers on platform advertising revenue for new versus existing buyers is larger in } \\
\text { the mature stage. }\end{array}$ & Supported \\
\hline $\begin{array}{l}\mathrm{H}_{6} \text { : In both stages, the direct positive effect of seller bid incentives on platform advertising revenue is greater for new than for existing } \\
\text { sellers }\end{array}$ & Supported \\
\hline \multicolumn{2}{|l|}{ Individual-Level Analysis of Behavioral Assumptions } \\
\hline New buyers click more search advertisements than existing buyers, especially in the established stage. & Supported \\
\hline $\begin{array}{l}\text { Existing sellers are more likely to bid higher than new sellers in the introduction stage, but in the established stage, new sellers tend to } \\
\text { bid higher than existing sellers. }\end{array}$ & Supported \\
\hline \multicolumn{2}{|l|}{ Keyword-Level Analysis of Informational Mechanisms } \\
\hline $\begin{array}{l}\text { In the introduction stage, existing sellers can more effectively use search advertising to send quality signals and generate buyer } \\
\text { awareness. }\end{array}$ & Supported \\
\hline In the established stage, new sellers can more effectively use search advertising to send quality signals and generate buyer awareness. & $\begin{array}{l}\text { Partially } \\
\text { supported }\end{array}$ \\
\hline
\end{tabular}

vated to improve the match between buyer keyword searches and their own products. In the launch stage, the higher bidding prices paid by existing sellers motivate them to improve their keyword match quality, so existing sellers exert a greater effect on click rate than new sellers; in the mature stage, because new sellers tend to outbid existing sellers and are more motivated to improve their keyword match quality, the quality effect is stronger for new than existing sellers. Second, acquiring buyers to use keyword search advertising also increases click price on the seller side because of the competition effect. As more buyers participate in search activities, competition among sellers intensifies, leading to a higher click price. Because sellers know that new, but not existing, buyers tend to click more ads, when more new buyers participate in the keyword search, competition intensifies further, increasing click price; this difference is especially pronounced in the mature stage.

Second, we explicitly model the effect of new and existing buyers and sellers on not only advertising revenue but also click price and click rate. Existing literature has focused mostly on quantity (i.e., sizes of two user networks; Trusov, Bucklin, and Pauwels 2009; Zhang et al. 2012), whereas we distinguish buyer and seller effects by quantity versus quality. By attracting new and existing buyers and sellers to participate in online advertising, the platform can improve its user quality, reflected in click rate on the buyer side and click price on the seller side. Focusing solely on increasing the user base while neglecting user quality may lead to a biased view of the true determinants of advertising revenue. For example, in contrast with the conventional wisdom that more existing buyers conducting keyword searches should increase advertising revenues, our results show that existing buyers do not change advertising revenues, particularly in the mature stage. However, this result makes sense if we consider the quality aspect: existing buyers do not affect buyer quality (click rate) or seller quality (click price).

Third, the customer relationship management literature has emphasized the importance of balancing the acquisition of new customers (exploration) with the retention of existing ones (exploitation) to enhance financial performance (Reinartz, Thomas, and Kumar 2005). Our results suggest that in a platform market, finding a balance between new and existing buyers and sellers demands consideration of specific stages of service development. Although conducting acquisition activities to attract new and existing buyers and sellers in the launch stage contributes to platform advertising revenues, the firm should focus on new buyers and sellers in the mature stage.

\section{Managerial Implications}

A platform can enhance its search advertising revenue by designing appropriate user acquisition and retention strategies, which should be adjusted to match the stages of its search advertising service. Platforms also should pay attention to both the size of their buyer and seller bases and the quality of these users, in terms of buyers' click rate and sellers' click price. 
On the seller side, the platform might provide incentives, such as free bidding or financial subsidies, to encourage bidding behaviors. On the buyer side, the platform could use external advertising tools, such as external search engines, to attract new buyers or turn to internal advertising tools, such as instant messages and e-mail notifications, to attract existing buyers. Such activities affect platform search advertising revenue in multiple ways. First, in the launch stage, existing sellers bid higher than new sellers, whereas the opposite holds in the mature stage. For buyers, new buyers exhibit a higher click rate than existing buyers, especially in the mature stage. Second, a strong crossover network effect exists such that strategies on the buyer side affect the seller's click price, and strategies on the seller side affect the buyer's click rate. Third, increasing the user base can create network effects, so more buyers and sellers participate and contribute to search advertising revenue. After the service has become well accepted, the platform should shift its resources to focus primarily on acquiring new buyers and sellers.

Finally, investing in activities such as external search advertising or internal bidding subsidies pays off, albeit to varying degrees. With regard to external search advertising, in the launch stage, a $\$ 1$ investment generated approximately $\$ 5$ more in search advertising revenues, and in the mature stage, this return grew to more than $\$ 10$. Furthermore, providing bidding credits of $\$ 1$ to sellers can yield from $\$ .07$ to $\$ .26$ (depending on new/existing sellers and stages). However, such returns are specific to our context.

\section{Limitations and Future Research Directions}

As with any research, this study is subject to several limitations. First, our empirical analysis is intended to establish predictive causality, which does not always coincide with behavioral causality. Some of the behavioral mechanisms are subject to alternative explanations. Second, our data may involve self-selection bias, in that platform users may appear to be new not only because they naturally arrive late at the platform but also because they choose not to participate for various reasons. Due to the cross-sectional data at the individual and keyword levels, our reduced-form regression analyses at these levels cannot capture the dynamic patterns of buyer clicking and seller bidding behaviors. Future studies might adopt alternative techniques (field experiments) to test for behavioral causality and control for self-selection biases.

Third, data limitations prevented us from modeling how product- and category-level heterogeneity affect buyer and seller behaviors and, thus, search advertising revenues. For example, information asymmetry and search costs may be contingent on the purchase frequency of the product such that the observed contrasts between new and existing buyers and sellers and the launch and mature stages could vary across product categories. These limitations also prevent us from controlling for individual-level factors that may affect clicking and bidding behaviors. Additional studies could collect data at the matched buyer-seller keyword levels. For example, researchers could gather user reviews and information about product quality, branding at the individualseller level, buyer experience at the individual-buyer level, and keyword characteristics and then adopt a structural approach to explore buyers' clicking behaviors, sellers' bidding behaviors, and their interactions simultaneously.

\section{APPENDIX B: KEYWORD-LEVEL MODEL SPECIFICATION}

We specified the following model for the keyword-level analysis and estimated it using ordinary least squares:

$$
\begin{aligned}
\text { Buyer clicks }_{\mathrm{i}, \mathrm{j}} & =\alpha_{1}+\alpha_{2} \text { keyword bidding price }_{\mathrm{i}} \\
& +\alpha_{3} \text { keyword popularity }_{\mathrm{i}}+\alpha_{4} \text { seller history }_{\mathrm{j}} \\
& +\alpha_{5} \text { stage_dummy }+\alpha_{6} \text { keyword bidding price }_{\mathrm{i}} \\
& \times \text { seller history }_{\mathrm{j}}+\alpha_{7} \text { keyword popularity }_{\mathrm{i}}
\end{aligned}
$$

\section{Appendix A}

INDIVIDUAL-LEVEL ANALYSIS RESULTS

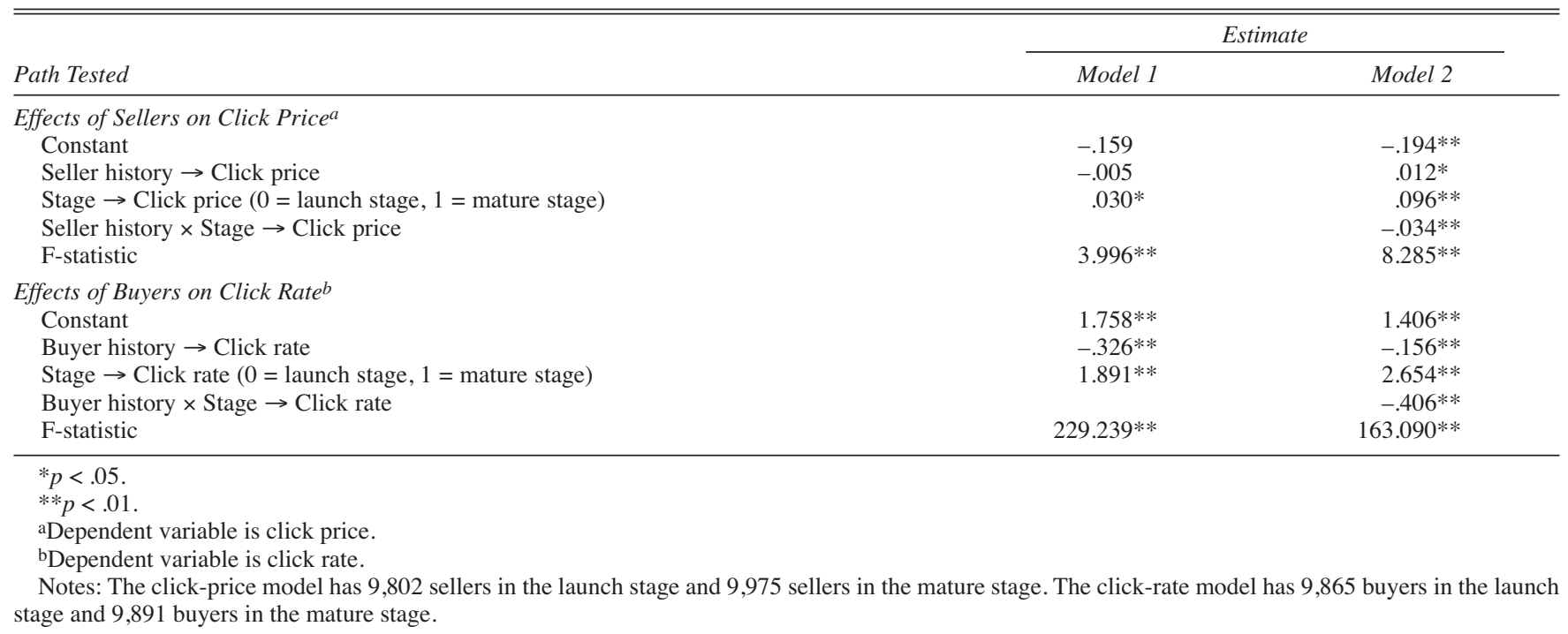


Table B1

KEYWORD-LEVEL ANALYSIS RESULTS

\begin{tabular}{lcc}
\hline \hline & \multicolumn{2}{c}{ Estimate } \\
\cline { 2 - 3 } Path Tested & Model 1 & Model 2 \\
\hline Constant & $10.130^{* *}$ & $10.212^{* *}$ \\
Keyword bidding price & -1.012 & $-1.553^{* *}$ \\
Keyword popularity & $.167^{* *}$ & $.102^{* *}$ \\
Seller history & $.163^{* *}$ & $.244^{* *}$ \\
Stage $(0=$ launch stage, $1=$ mature stage $)$ & $.129^{* *}$ & .035 \\
Keyword bidding price $\times$ Seller history & $.301^{* *}$ & $.164^{* *}$ \\
Keyword popularity $\times$ Seller history & .007 & $.218^{* *}$ \\
Keyword bidding price $\times$ Seller history $\times$ Stage & $-.254^{*}$ \\
Keyword popularity $\times$ Seller history $\times$ Stage & $-.178^{* *}$ \\
F-statistic & $83.949^{* *}$ & $134.958^{* *}$ \\
\hline
\end{tabular}

$* p<.05$.

$* * p<.01$

Notes: Dependent variable is number of buyer clicks.

$$
\begin{aligned}
& \times \text { seller history }_{\mathrm{j}}+\alpha_{8}{\text { keyword bidding } \text { price }_{\mathrm{i}}} \\
& \times \text { seller history }_{\mathrm{j}} \times \text { stage_dummy } \\
& +\alpha_{9} \text { keyword popularity }_{\mathrm{i}} \times \text { seller history } \\
& \mathrm{j} \\
& \times \text { stage_dummy }+\varepsilon_{\mathrm{i}, \mathrm{j}},
\end{aligned}
$$

where Buyer clicks ${ }_{i, j}$ is the number of total buyer clicks of keyword $\mathrm{i}$ by seller $\mathrm{j}$.

\section{REFERENCES}

Athey, Susan and Glenn Ellison (2011), "Position Auctions with Consumer Search," Quarterly Journal of Economics, 126 (3), 1213-70.

Carson, Stephen J., Timothy M. Devinney, Grahame R. Dowling, and George John (1999), "Understanding Institutional Designs Within Marketing Value Systems," Journal of Marketing, 63 (Special Issue), 115-30.

Dekimpe, Marnik G. and Dominique M. Hanssens (1999), "Sustained Spending and Persistent Response: A New Look at LongTerm Marketing Profitability," Journal of Marketing Research, 23 (November), 397-412.

Dou, Wenyu, Kai H. Lim, Chenting Su, Nan Zhou, and Nan Cui (2010), "Brand Positioning Strategy Using Search Engine Marketing," MIS Quarterly, 34 (2), 261-79.

Eisenhardt, Kathleen M. (1989), "Making Fast Strategic Decisions in High-Velocity Environments," Academy of Management Journal, 32 (3), 543-76.

eMarketer (2011), "Online Advertising Market Poised to Grow $20 \%$ in 2011," press release, (June 8), (accessed March 2, 2015), [available at http://www.emarketer.com/newsroom/index.php/ online-advertising-market-poised-grow-20-2011/].

Enders, Walter (1995), Applied Econometric Time Series. New York: John Wiley \& Sons.

Fang, Eric (Er) (2008), "Customer Participation and the Trade-Off Between New Product Innovativeness and Speed to Market," Journal of Marketing, 72 (July), 90-104.

Feng, Juan and Jinhong Xie (2012), "Performance-Based Advertising: Advertising as Signals of Product Quality," Information Systems Research, 23 (3, Part 2), 1030-41.

Granger, Clive W.J. (1969), "Investigating Causal Relations by Econometric Models and Cross-Spectral Methods," Econometrica, 37 (3), 424-38.

Grewal, Rajdeep, Anindita Chakravarty, and Amit Saini (2010), "Governance Mechanisms in Business-to-Business Electronic Markets," Journal of Marketing,74 (July), 45-62.
Gu, Flora F., Namwoon Kim, David K. Tse, and Danny T. Wang (2010), "Managing Distributors' Changing Motivations over the Course of a Joint Sales Program," Journal of Marketing, 74 (September), 32-47.

Inclán, Carla and George C. Tiao (1994), "Use of Cumulative Sums of Squares for Retrospective Detection of Changes of Variance," Journal of the American Statistical Association, 89 (427), 913-23.

Joshi, Amit and Dominique M. Hanssens (2010), "The Direct and Indirect Effects of Advertising Spending on Firm Value," Journal of Marketing, 74 (January), 20-33.

Katona, Zsolt and Miklos Sarvary (2010), "The Race for Sponsored Links: Bidding Patterns for Search Advertising," Marketing Science, 29 (2), 199-215.

Katz, Michael and Carl Shapiro (1994), "Systems Competition and Network Effects," Journal of Economic Perspectives, 8 (2), 93 115 .

Kirmani, Amna and Akshay R. Rao (2000), "No Pain, No Gain: A Critical Review of the Literature on Signaling Unobservable Product Quality," Journal of Marketing, 64 (April), 66-79.

Mishra, Debi Prasad, Jan B. Heide, and Stanton G. Cort (1998), "Information Asymmetry and Levels of Agency Relationships," Journal of Marketing Research, 35 (August), 277-95.

Nijs, Vincent R., Shuba Srinivasan, and Koen Pauwels (2007), "Retail-Price Drivers and Retailer Profits," Marketing Science, 26 (4), 473-87.

Pauwels, Koen and Enrique Dans (2001), "Internet Marketing the News: Leveraging Brand Equity from Marketplace to Marketspace," Journal of Brand Management, 8 (4), 303-314.

— and Allen Weiss (2008), "Moving from Free to Fee: How Online Firms Market to Change Their Business Model Successfully," Journal of Marketing, 72 (May), 14-31.

Reinartz, Werner, Jacquelyn S. Thomas, and V. Kumar (2005), "Balancing Acquisition and Retention Resources to Maximize Customer Profitability," Journal of Marketing, 69 (January), 63-79.

Rust, Roland T., Kathleen N. Lemon, and Valarie A. Zeithaml (2004), "Return on Marketing: Using Customer Equity to Focus Marketing Strategy," Journal of Marketing, 68 (January), 109127.

Rutz, Oliver J. and Randolph E. Bucklin (2011), "From Generic to Branded: A Model of Spillover Dynamics in Paid Search Advertising," Journal of Marketing Research, 48 (February), 87-102.

_ Michael Trusov, and Randolph E. Bucklin (2011), "Modeling Indirect Effects of Paid Search Advertising: Which Keywords Lead to More Future Visits?" Marketing Science, 30 (4), 646-65. 
Sims, Christopher (1980), "Macroeconomics and Reality," Econometrica, 48 (1), 1-48.

Spiller, Stephen, Gavan Fitzsimons, John Lynch, and Gary McClelland (2013), "Spotlights, Floodlights, and the Magic Number Zero: Simple Effects Tests in Moderated Regression," Journal of Marketing Research, 50 (April), 277-88

Trusov, Michael, Randolph E. Bucklin, and Koen Pauwels (2009), "Effects of Word-of-Mouth Versus Traditional Marketing: Findings from an Internet Social Networking Site," Journal of Marketing, 73 (September), 90-102.

Tucker, Catherine and Juanjuan Zhang (2010), "Growing TwoSided Networks by Advertising the User Base: A Field Experiment," Marketing Science, 29 (5), 805-814.

Villanueva, Julian, Shijin Yoo, and Dominique M. Hanssens (2008), "The Impact of Marketing-Induced Versus Word-ofMouth Customer Acquisition on Customer Equity Growth," Journal of Marketing Research, 45 (February), 48-59.

Wang, Qi and Jinhong Xie (2011), "Will Consumers Be Willing to Pay More When Your Competitors Adopt Your Technology? The Impacts of the Supporting-Firm Base in Markets with Network Effects," Journal of Marketing, 75 (September), 1-17.
Wiesel, Thorsten, Koen Pauwels, and Joep Arts (2011), "Marketing's Profit Impact: Quantifying Online and Offline Funnel Progression," Marketing Science, 30 (4), 604-611.

Xu, Lizhen, Jianqing Chen, and Andrew B. Whinston (2011), "Price Competition and Endogenous Valuation in Search Advertising," Journal of Marketing Research, 48 (June), 566-86.

Yang, Sha and Anindya Ghose (2010), "Analyzing the Relationship Between Organic and Sponsored Search Advertising: Positive, Negative, or Zero Interdependence?" Marketing Science, 29 (4), 602-623.

Yao, Song and Carl F. Mela (2011), "A Dynamic Model of Sponsored Search Advertising," Marketing Science, 30 (3), 447-68.

Zhang, Kaifu, Theodoros Evgeniou, V. Padmanabhan, and Emile Richard (2012), "Content Contributor Management and Network Effects in a UGC Environment," Marketing Science, 31 (3), 433-47.

Zhu, Feng and Marco Iansiti (2012), "Entry into Platform-Based Markets," Strategic Management Journal, 33 (1), 88-106. 


\title{
WEB APPENDIX
}

\section{Direct and Indirect Effects of Buyers and Sellers on Search Advertising Revenues in Business-to-Business Electronic Platforms}

\author{
Eric (Er) Fang \\ Xiaoling Li \\ Minxue Huang \\ Robert W. Palmatier
}

Note: The second author acknowledges the financial support of the National Science Foundation of China Grant (No. 71202180), and the third author acknowledges the financial support of The National Natural Science Foundation of China (No. 7137272127). 
Web Appendix A: Impulse Response Function

FIGURE A1: Impulse Response Function of New Buyers to Platform Advertising Revenue: Launch Stage

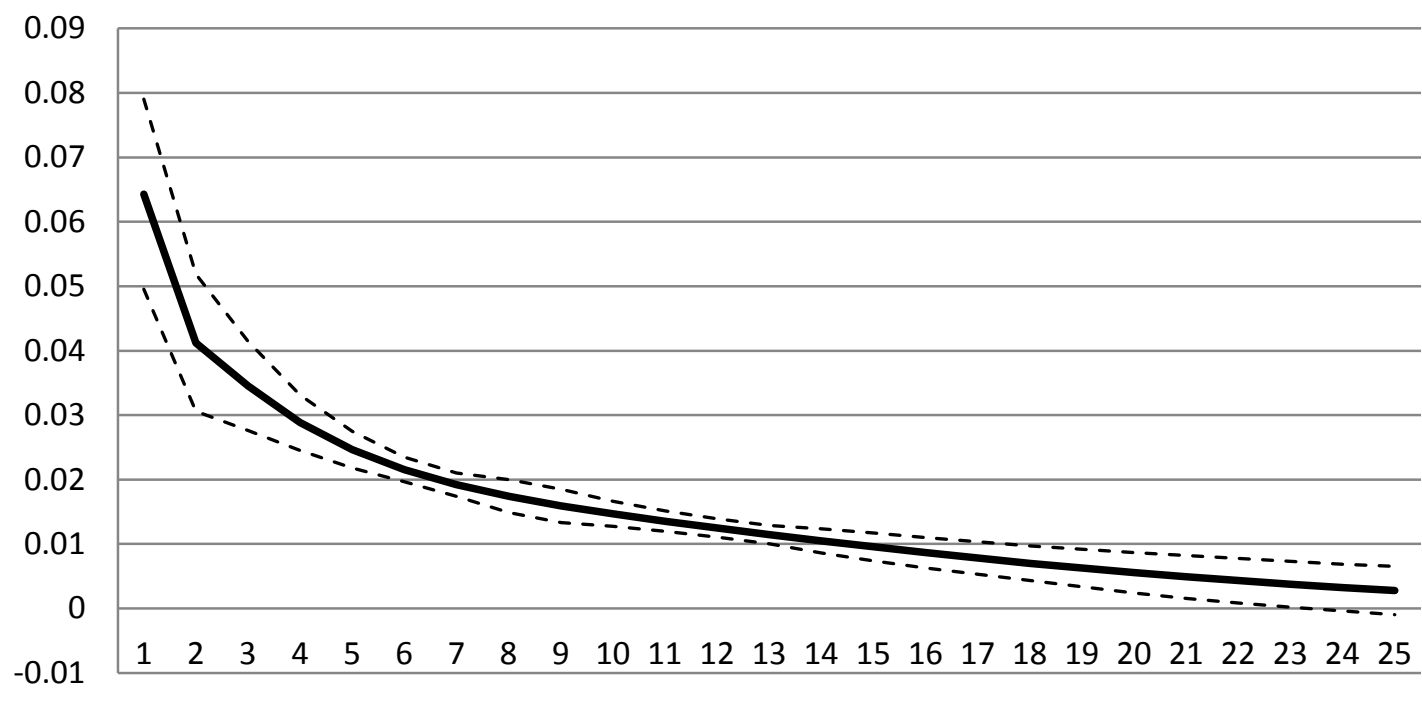

Days

Buyer exploration effects on Revenue +1 SD - - - - - - 1 SD

FIGURE A2: Impulse Response Function of New Buyers to Platform Advertising Revenue: Mature Stage

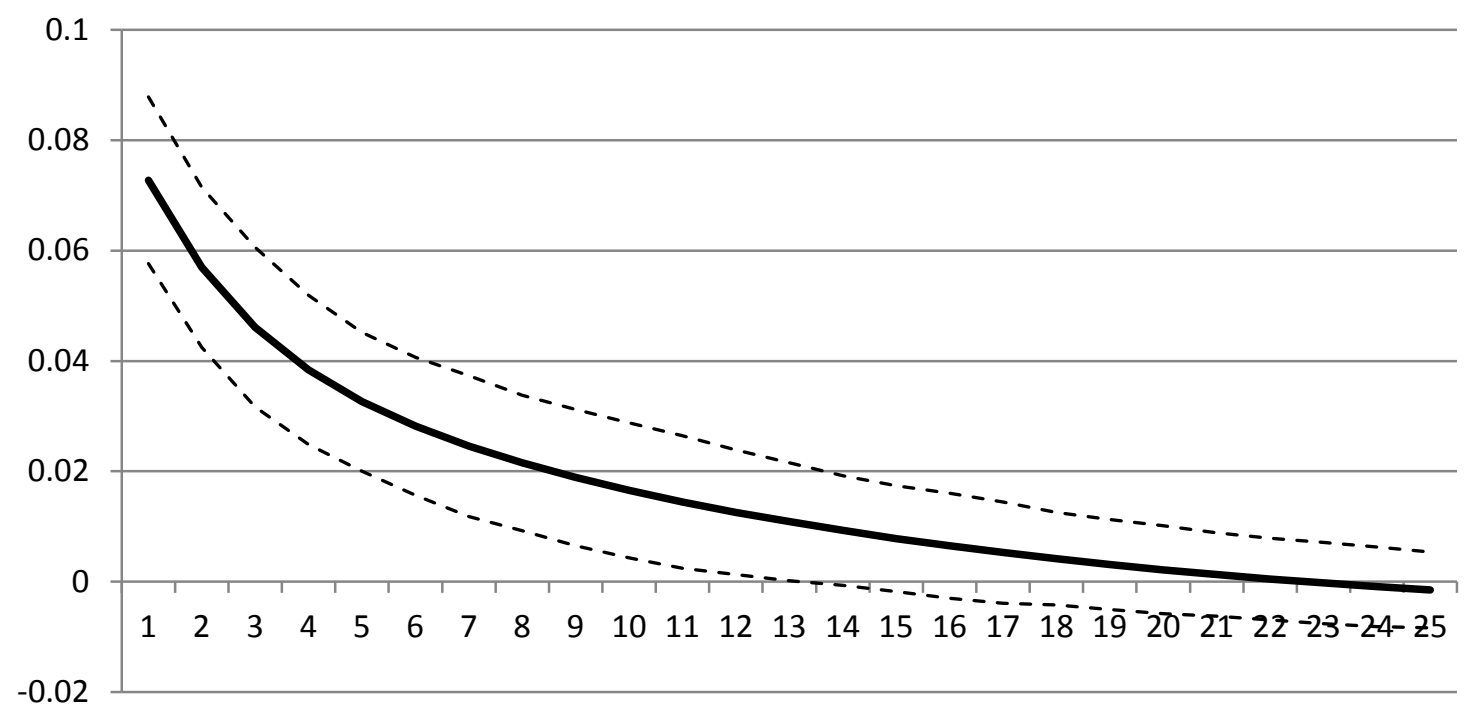

Buyer exploration effects on Revenue +1 SD --.--.-- -1 SD 
FIGURE A3: Impulse Response Function of Existing Buyers to Platform Advertising Revenue: Launch Stage

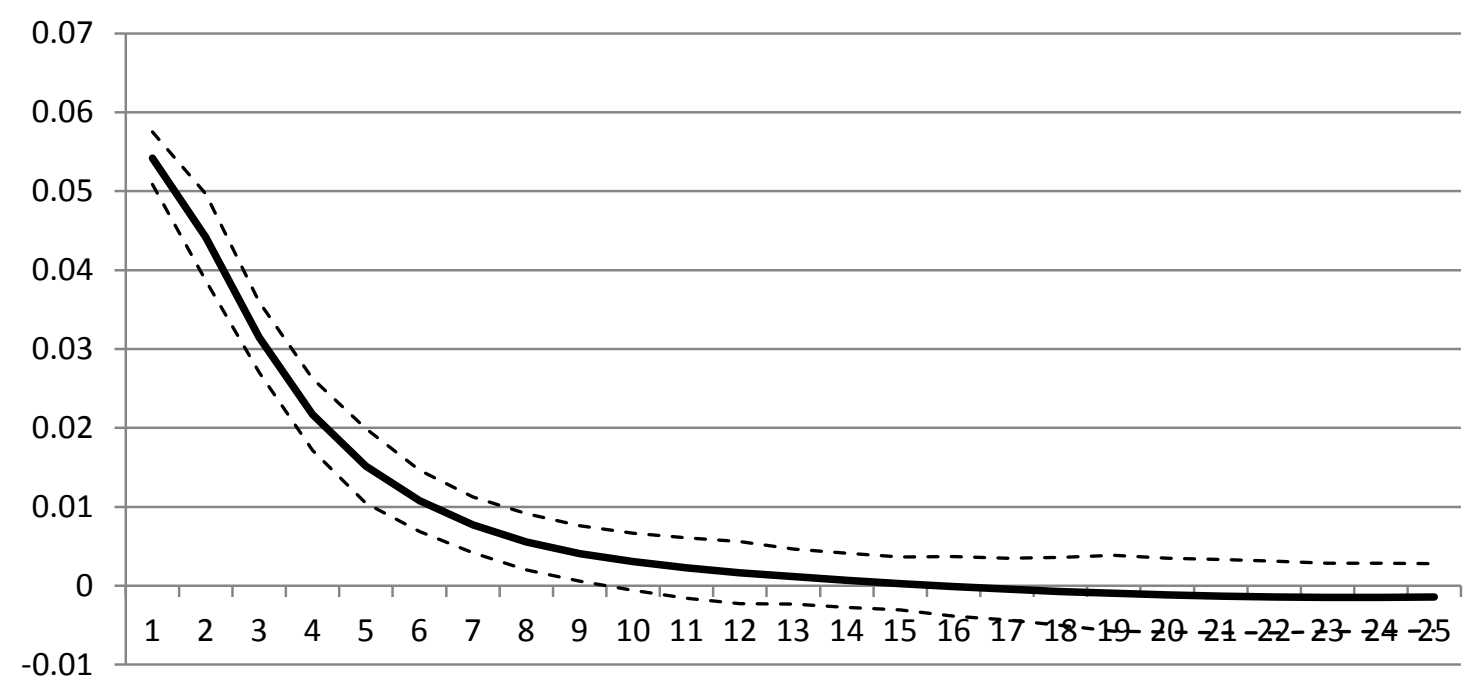

Days

Buyer exploitation effects on Revenue

+1 SD

FIGURE A4: Impulse Response Function of New Sellers to Platform Advertising Revenue: Launch Stage

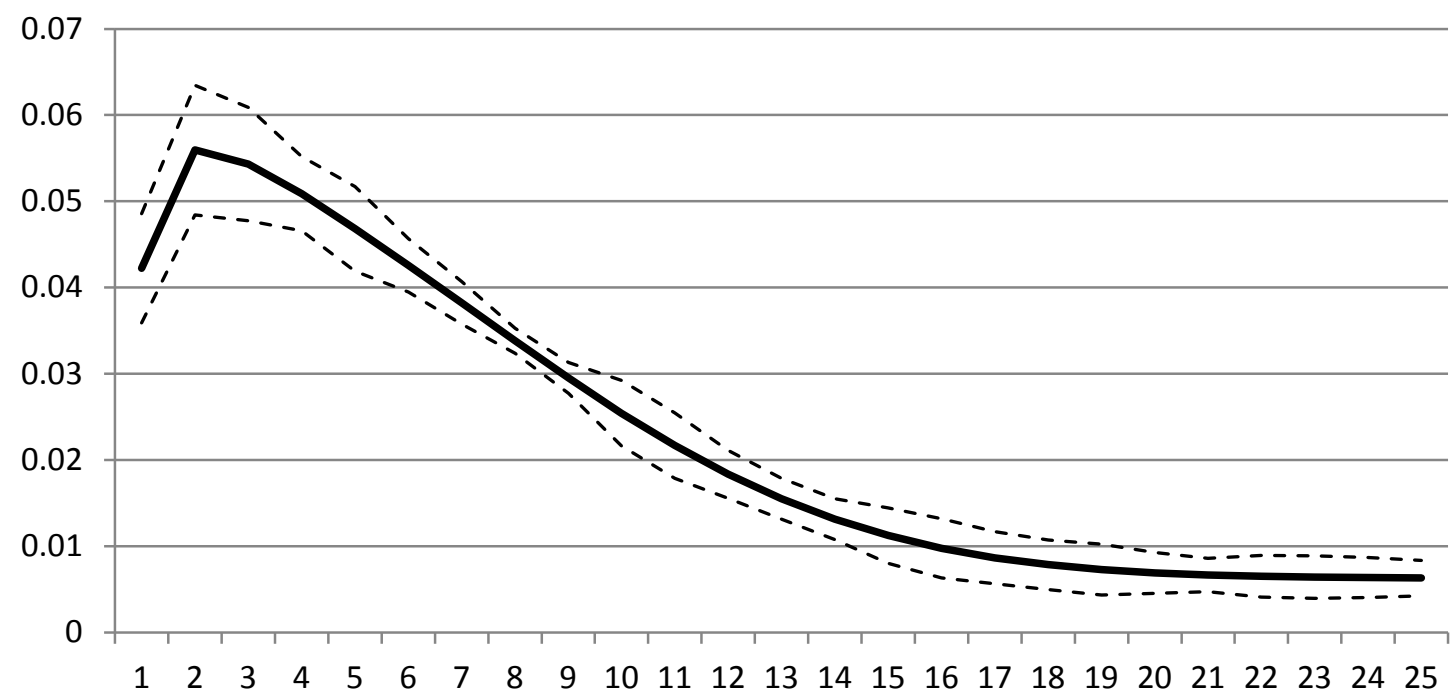

Seller exploration effects on Revenue $+1 \mathrm{SD} \quad-\cdots-\ldots-1 \mathrm{SD}$ 
FIGURE A5: Impulse Response Function of New Sellers to Platform Advertising Revenue: Mature Stage

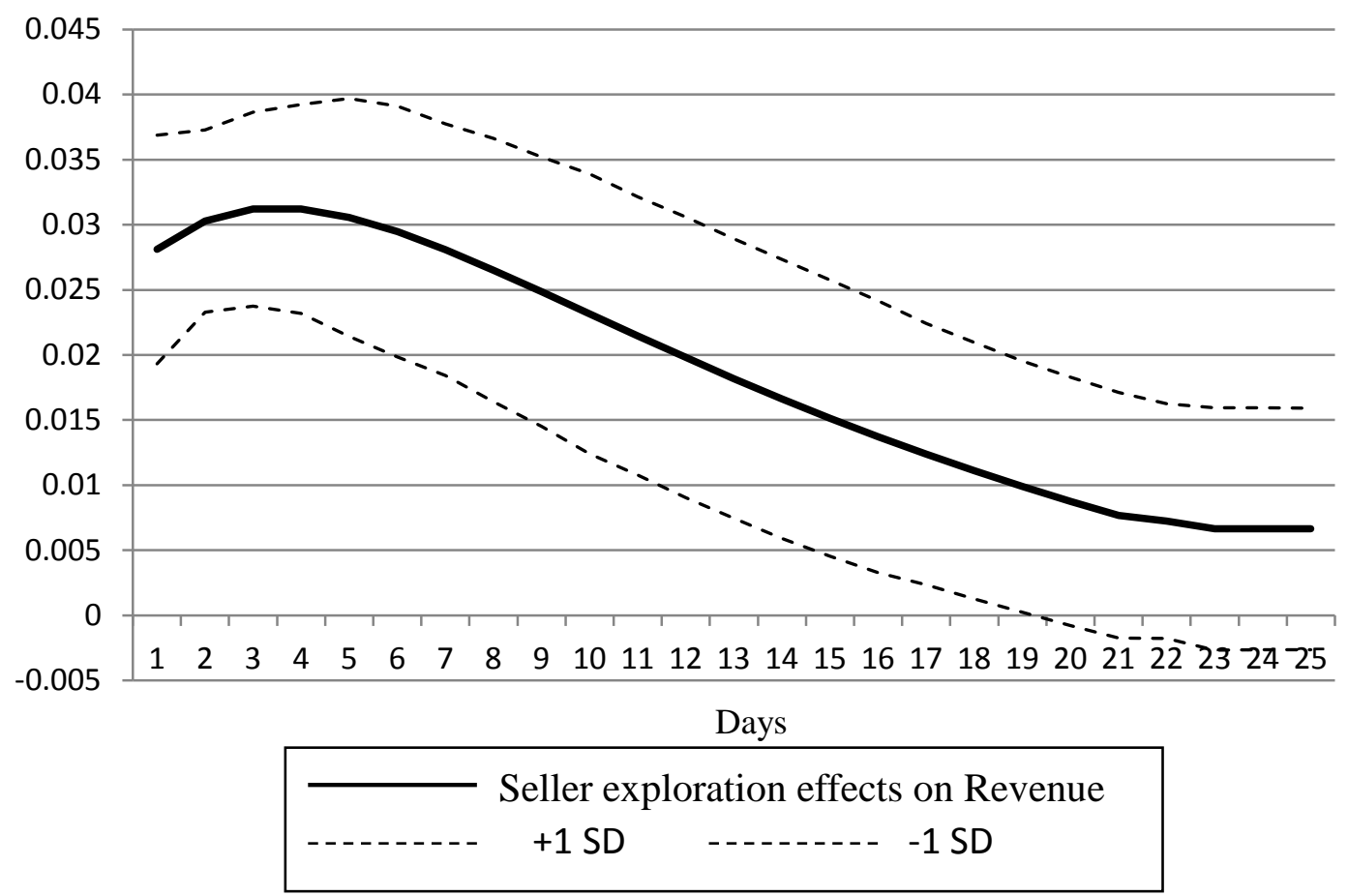

FIGURE A6: Impulse Response Function of Existing Sellers to Platform Advertising Revenue: Launch Stage

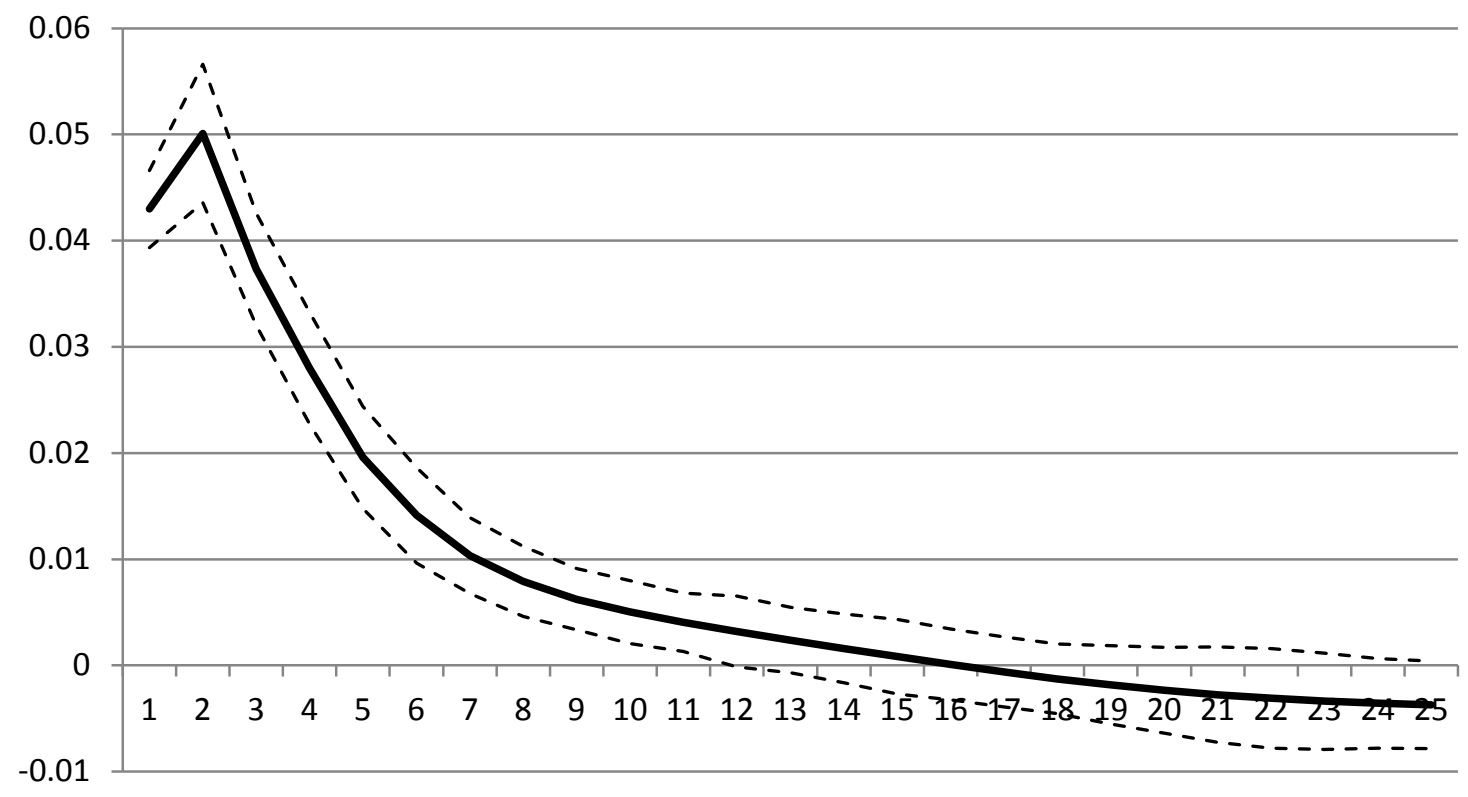

Seller exploitation effects on Revenue +1 SD -.-.-.-- -1 SD 


\section{Web Appendix B: Elasticity}

In this section, we present the total effect or elasticity of attracting new and existing buyers (sellers), generated from the IRF, on advertising revenue; this total effect includes indirect effects through PPC and CTR, together with the direct effects. The results show that in the launch stage, new sellers had the greatest effect, with an elasticity of .440, followed by new buyers (.321), existing sellers (.187), and existing buyers (.148). The order of the effect sizes was consistent with Zhang et al.'s (2012) examination of commission revenues. In the mature stage, only new buyers and sellers influenced the platform firm's advertising revenues, and the elasticity of new buyers (.469) was significantly greater than that in the launch stage; in contrast, new sellers' elasticity remained similar across stages (.430).

\begin{tabular}{lll}
\hline & Launch Stage & Mature Stage \\
\hline New buyers & $0.321^{* * *}$ & $0.430^{* * *}$ \\
Existing buyers & $0.148^{* * *}$ & $0.031^{\text {n.s. }}$ \\
New sellers & $0.440^{* * *}$ & $0.469^{* * *}$ \\
Existing sellers & $0.187^{* * *}$ & $0.000^{\text {n.s. }}$ \\
F** $_{p<.001 .}$ &
\end{tabular}




\section{Web Appendix C: Change Point Analysis}

In order to identify the two development stage of search advertising, we also applied change point analysis proposed by Inclán and Tiao (1994), which is a type of formal test for the detection of multiple changes of variance. The unique advantage for Inclán and Tiao (1994)'s approach is that it is appropriate for large T (e.g. 1000) with the objective to find structural breaks in the (unconditional) variance with unknown locations, whereas most other approaches are develop to identify the point of change in a sequence of random variables with small T (Andreou and Ghysels 2002; Zivot and Andrews 1992; Poon and Granger 2003). Considering our time sample size of $\mathrm{T}=$ 882, which is close to 1000 , we decided to follow the approach by Inclán and Tiao (1994).

\section{Procedure to detect change points}

The procedure of change point analysis runs in several steps.

First, let $\mathrm{Y}_{\mathrm{k}}$ be a given sequence of observations; based on the analysis of Brown et al.(1975), recursive residuals $a_{\mathrm{i}}$ can be expressed in terms $\mathrm{Y}_{\mathrm{k}}$ as

$$
a_{k}=\frac{Y_{k}-\left(\sum_{i=0}^{k-1} Y_{i} / k\right)}{\sqrt{\left(\frac{k+1}{k}\right) S_{Y}^{2}}} \mathrm{k}=1,2,3, \ldots \ldots, \mathrm{T}
$$

Second, let $C_{k}=\sum_{i=1}^{k} a_{i}^{2}$ be the cumulative sum of squares of a series of uncorrelated random variables $\left\{\mathrm{a}_{\mathrm{t}} \mid \mathrm{i}=1,2, \ldots, \mathrm{T}\right\}$ with mean 0 and variances $\sigma^{2}$. Third, let $D_{k}=\frac{C_{k}}{C_{T}}-\frac{k}{T}, \mathrm{k}=1,2, \ldots \mathrm{T}$, with $\mathrm{D}_{0}=\mathrm{D}_{\mathrm{T}}=0$ be the centered (and normalized) cumulative sum of squares. 
The plot of $D_{k}$ against $k$ will oscillate around 0 for series with homogeneous variance. When there is a sudden change in variance, the plot of $D_{k}$ will exhibit a pattern going out of some specified boundaries with high probability, creating a peak or a tough depending on the directions of such variance changes.

Furthermore, the asymptotic distribution of $\mathrm{D}_{\mathrm{k}}$ follows a Brownian motion process when the random variables $\left\{\mathrm{a}_{\mathrm{t}}\right\}$ are identically distributed. Let $\mathrm{W}^{0}$ represent a Brownian motion process, and following the proof of Inclán and Tiao (1994), $\sqrt{\frac{\mathrm{n}}{2}}$ $\mathrm{D}_{\mathrm{k}} \stackrel{\mathfrak{D}}{\rightarrow} \mathrm{W}^{0}$. This asymptotic distribution determines the probability $\mathrm{P}\left\{\sup _{\mathrm{t}}\left|\mathrm{W}_{\mathrm{t}}^{0}\right|<\mathrm{D}^{*}\right\}$, so that asymptotic quantiles of $\max _{k}\left|D_{k}\right|$ can be obtain. Based on Inclán and Tiao (1994), Table C1 compares selected asymptotic quantiles of $\max _{k}\left|D_{k}\right|$ with corresponding empirical quantiles for various series lengths obtained through simulations. Table C1 suggests the asymptotic critical value of $\mathrm{D}^{*}$ equals 1.358 with95\% confidence interval, when t is larger than 500 .

Results. We used platform revenue as input to detect change points. As shown in Figure C1, two change points appear in the time window. The first one is October 25, 2009, and the second one is January 26, 2011. As a result, we consider April 1, 2009 to October 25, 2009 as launch stage (last for 207 days), and January 26, 2011 to August 31, 2011 as mature stage (last for 215 days). The model analayes based on these two time windows grenerate consistent results with those based on time windows using structural break approach. 
Table C1: Empirical and Asymptotic Quantiles of maxk $\sqrt{\frac{n}{2}}\left|D_{k}\right|$

\begin{tabular}{|c|c|c|c|c|c|c|c|c|c|c|c|}
\hline $\mathrm{T}$ & \multicolumn{2}{|c|}{100} & \multicolumn{2}{|c|}{200} & \multicolumn{2}{|c|}{300} & \multicolumn{2}{|c|}{400} & \multicolumn{2}{|c|}{500} & \multirow{2}{*}{$\begin{array}{c}\infty \\
\mathbf{D}_{1-\mathbf{p}}^{*}\end{array}$} \\
\hline $\mathrm{p}$ & $\mathrm{q}_{\mathrm{D}}$ & SE & $\mathrm{q}_{\mathrm{D}}$ & $\mathrm{SE}$ & $\mathrm{q}_{\mathrm{D}}$ & SE & $\mathrm{q}_{\mathrm{D}}$ & $\mathrm{SE}$ & $\mathrm{q}_{\mathrm{D}}$ & $\mathrm{SE}$ & \\
\hline .05 & .44 & .003 & .47 & .003 & .47 & .003 & .48 & .003 & .049 & .003 & .520 \\
\hline . 10 & .50 & .003 & .52 & .003 & .53 & .003 & .53 & .003 & .054 & .002 & .571 \\
\hline .25 & .60 & .004 & .63 & .004 & .63 & .003 & .64 & .003 & .065 & .003 & .677 \\
\hline .50 & .75 & .004 & .78 & .004 & .78 & .003 & .79 & .003 & .080 & .003 & .828 \\
\hline .75 & .94 & .004 & .97 & .004 & .97 & .004 & .97 & .004 & 1.00 & .004 & 1.019 \\
\hline .90 & 1.14 & .006 & 1.16 & .006 & 1.18 & .007 & 1.18 & .006 & 1.20 & .006 & 1.224 \\
\hline .95 & 1.27 & .009 & 1.30 & .004 & 1.31 & .008 & 1.31 & .010 & 1.33 & .009 & 1.358 \\
\hline .99 & 1.52 & .004 & 1.55 & .012 & 1.57 & .008 & 1.57 & .020 & 1.60 & .01 & 1.628 \\
\hline
\end{tabular}




\section{FIGURE C1: The Result of Change Point Analysis}

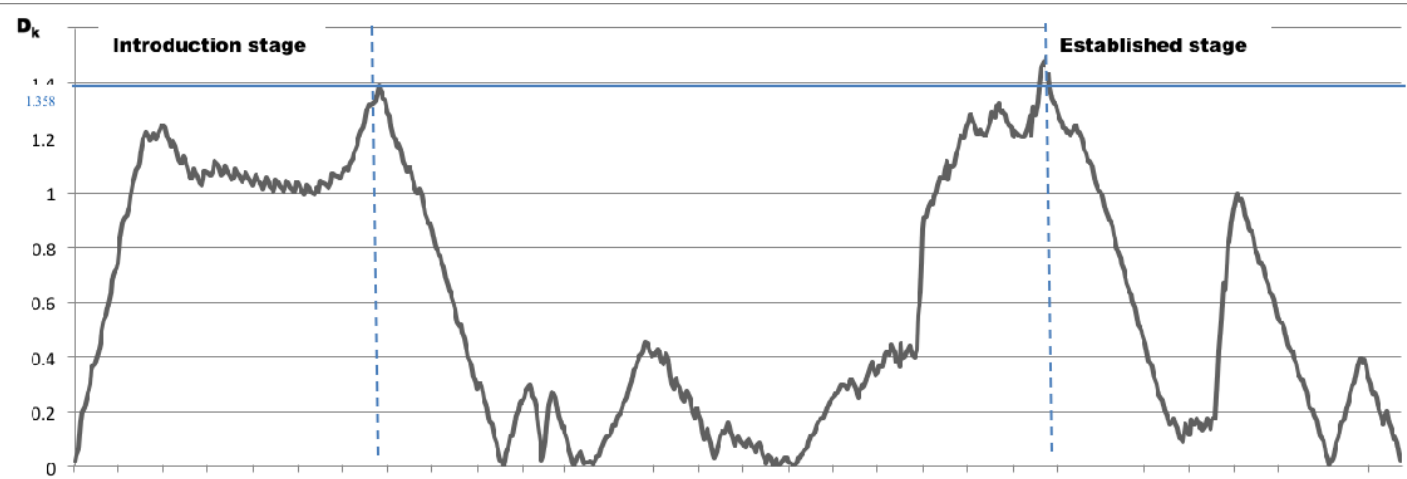

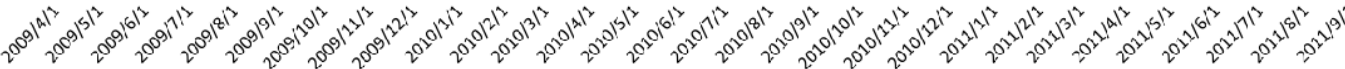




\section{References}

Andreou, Eland Ghysels, E. (2002), “Detecting multiple breaks in financial market volatility dynamics, “Journal of Applied Econometrics, 17(5), 579-600.

Brown, R. L., J. Durbin, and J. M. Evans (1975), “Techniques for testing the constancy of regression relationships over time,” Journal of the Royal Statistical Society. Series B (Methodological), 37(2), 149-192.

Poon, S. H.and Granger, C. W. (2003), “Forecasting volatility in financial markets: A review,” Journal of Economic Literature, 41(2), 478-539.

Inclan, C. and G.C. Tiao (1994): ”Use of Cumulative Sums of Squares for Retrospective Detection of Changes of Variance”. Journal of the American 
Copyright of Journal of Marketing Research (JMR) is the property of American Marketing Association and its content may not be copied or emailed to multiple sites or posted to a listserv without the copyright holder's express written permission. However, users may print, download, or email articles for individual use. 